\title{
Synthesis and characterization of magnetic nanolaminated carbides
}

\author{
Andrejs Petruhins
}

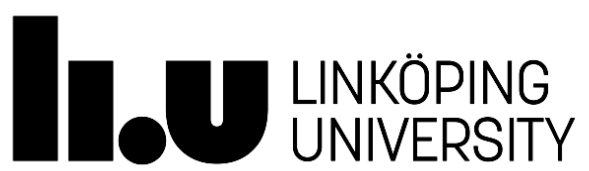

\author{
Materials Design \\ Thin Film Physics Division \\ Department of Physics, Chemistry and Biology (IFM) \\ Linköping University, SE-581 83, Linköping, Sweden \\ Linköping 2018
}


The cover image shows three different STEM-EDX maps of a $\mathrm{Mn}_{2} \mathrm{GaC}$ MAX phase thin film on a $\mathrm{MgO}$ substrate. The shown maps are for $\mathrm{Mn}$ (in blue), $\mathrm{Ga}$ (in green) and $\mathrm{C}$ (in red). This was one of the first confirmations of the existence of $\mathrm{Mn}_{2} \mathrm{GaC}$.

(C) Andrejs Petruhins, 2018

ISBN 978-91-7685-342-9

ISSN 0345-7524

Printed by LiU-Tryck, Linköping, 2018. 


\section{Abstract}

MAX phases are a group of nanolaminated ternary carbides and nitrides, with a composition expressed by the general formula $M_{n+1} A X_{n}(n=1-3)$, where $M$ is a transition metal, $A$ is an A-group element, and $X$ is carbon and/or nitrogen. MAX phases have attracted interest due to their unique combination of metallic and ceramic properties, related to their inherently laminated structure of a transition metal carbide $\left(M_{n+1} X_{n}\right)$ layer interleaved by an A-group metal layer.

This Thesis explores synthesis and characterization of magnetic MAX phases, where the A-group element is gallium $(\mathrm{Ga})$. Due to the low melting point of $\mathrm{Ga}\left(\mathrm{T}=30{ }^{\circ} \mathrm{C}\right)$, conventional thin film synthesis methods become challenging, as the material is in liquid form at typical process temperatures. Development of existing methods has therefore been investigated, for reliable/reproducible synthesis routes, including sputtering from a liquid target, and resulting high quality material. Routes for minimizing trial-and-error procedures during optimization of thin film synthesis have also been studied, allowing faster identification of optimal deposition conditions and a simplified transfer of essential deposition parameters between different deposition systems.

A large part of this Thesis is devoted towards synthesis of MAX phase thin films in the $\mathrm{Cr}-\mathrm{Mn}-\mathrm{Ga}-\mathrm{C}$ system. First, through process development, thin films of $\mathrm{Cr}_{2} \mathrm{GaC}$ were deposited by magnetron sputtering. The films were epitaxial, however with small amount of impurity phase $\mathrm{Cr}_{3} \mathrm{Ga}$, as confirmed by X-ray diffraction (XRD) measurements. The film structure was confirmed by scanning transmission electron microscopy (STEM) and the composition by energy dispersive X-ray spectroscopy (EDX) inside the TEM.

Inspired by predictive $a b$ initio calculations, the new $\mathrm{MAX}$ phase $\mathrm{Mn}_{2} \mathrm{GaC}$ was successfully synthesized in thin film form by magnetron sputtering. Structural parameters and magnetic properties were analysed. The material was found to have two magnetic transitions in the temperature range $3 \mathrm{~K}$ to $750 \mathrm{~K}$, with a first order transition at around $214 \mathrm{~K}$, going from non-collinear antiferromagnetic state at lower temperature to an antiferromagnetic state at higher temperature. The Neél temperature was determined to be $507 \mathrm{~K}$, changing from an antiferromagnetic to a paramagnetic state. Above $800 \mathrm{~K}, \mathrm{Mn}_{2} \mathrm{GaC}$ decomposes. Furthermore, magnetostrictive, magnetoresistive and magnetocaloric properties of the material were 
determined, among which a drastic change in lattice parameters upon the first magnetic transition was observed. This may be of interest for magnetocaloric applications.

Synthesis of both $\mathrm{Cr}_{2} \mathrm{GaC}$ and $\mathrm{Mn}_{2} \mathrm{GaC}$ in thin film form opens the possibility to tune the magnetic properties through a solid solution on the transition metal site, by alloying the aforementioned $\mathrm{Cr}_{2} \mathrm{GaC}$ with $\mathrm{Mn}$, realizing $\left(\mathrm{Cr}_{1-x} \mathrm{Mn}_{x}\right)_{2} \mathrm{GaC}$. From a compound target with a Cr:Mn ratio of $1: 1$, thin films of $\left(\mathrm{Cr}_{0.5} \mathrm{Mn}_{0.5}\right)_{2} \mathrm{GaC}$ were synthesized, confirmed by TEM-EDX. Optimized structure was obtained by deposition on $\mathrm{MgO}$ substrates at a deposition temperature of $600{ }^{\circ} \mathrm{C}$. The thin films were phase pure and of high structural quality, allowing magnetic measurements. Using vibrating sample magnetometry (VSM), it was found that $\left(\mathrm{Cr}_{0.5} \mathrm{Mn}_{0.5}\right)_{2} \mathrm{GaC}$ has a ferromagnetic component in the temperature range from $30 \mathrm{~K}$ to $300 \mathrm{~K}$, with the measured magnetic moment at high field decreasing by increasing temperature. The remanent moment and coercive field is small, $0.036 \mu_{\mathrm{B}}$, and $12 \mathrm{mT}$ at $30 \mathrm{~K}$, respectively. Using ferromagnetic resonance spectroscopy, it was also found that the material has pure spin magnetism, as indicated by the determined spectroscopic splitting factor $\mathrm{g}=2.00$ and a negligible magnetocrystalline anisotropy energy.

Fuelled by the recent discoveries of in-plane chemically ordered quaternary MAX phases, so called $i$-MAX phases, and guided by ab initio calculations, new members within this family, based on $\mathrm{Cr}$ and $\mathrm{Mn}$, were synthesized by pressureless sintering methods, realizing $\left(\mathrm{Cr}_{2 / 3} \mathrm{Sc}_{1 / 3}\right)_{2} \mathrm{GaC}$ and $\left(\mathrm{Mn}_{2 / 3} \mathrm{Sc}_{1 / 3}\right)_{2} \mathrm{GaC}$. Their structural properties were determined. Through these phases, the Mn content is the highest obtained in a bulk MAX phase to date.

This work has further developed synthesis processes for sputtering from liquid material, for an optimized route to achieve thin films of controlled composition and a high structural quality. Furthermore, through this work, Mn has been added as a new element in the family of MAX phase elements. It has also been shown, that alloying with different content of Mn gives rise to varying magnetic properties in MAX phases. As a result of this Thesis, it is expected that the MAX phase family can be further expanded, with more members of new compositions and new properties. 


\section{POPULÄRVETENSKAPLIG SAMMANFATTNING}

Genom alla tider har mänskligheten strävat mot en förbättring genom att utveckla nya material och redskap. Nya uppfinningar och material har påverkat utvecklingen av vår civilisation, så till den grad att perioder i historien har kallats efter de material som använts, t.ex. sten- eller järnålder. Idag lever vi i en modern tid med ett väl utvecklat samhälle, delvis beroende på alla de avancerade material som finns i t.ex. mobiltelefoner, datorer, kompakta lagringsmedia. Utvecklingen går ändå framåt och i och med detta ställs nya, ännu högre krav på framtidens material.

Alla material består av atomer, och ska man förklara hur ett nanolaminerat material ser ut på atomnivå, är det enklast om man föreställer sig en tårta med många staplade lager. I ett nanolaminerat material består varje enskild lager av en specifik typ av atomer, som i rätt ordning kan bilda de material som är i fokus i denna avhandling: MAX-faser. MAX-faser består oftast av minst tre olika atomslag: $M$ är en övergångsmetall (t.ex. krom), $A$ är en metall/halvmetall (t.ex. gallium) och $X$ är kol eller kväve. När materialet innehåller kol, kallas det för karbid, däremot kallas det för nitrid, om det bildas med kväve. Dessa material har tack vare sin nanolaminerade struktur en unik kombination av både metalliska och keramiska egenskaper.

I den här avhandlingen har jag skapat och undersökt egenskaper hos flera MAX-faser och har lagt fokus på karbider med magnetiska egenskaper. Alla inkluderade material har gallium som $A$ element, vilket har en låg smälttemperatur på ca $30{ }^{\circ} \mathrm{C}$. Det betyder att den metod för materialsyntes som använts för att göra tunna skikt, så kallad magnetron sputtring, måste vidareutvecklas för att den skulle kunna användas för gallium.

Med en vidareutvecklad metod kunde jag för första gången syntetisera $\mathrm{Cr}_{2} \mathrm{GaC}$ MAX-fas i form av tunna filmer. Genom att delvis byta ut hälften av $\mathrm{Cr}$ (krom) atomerna mot $\mathrm{Mn}$ (mangan) i $\mathrm{Cr}_{2} \mathrm{GaC}$, kunde dessutom ett nytt material, $\left(\mathrm{Cr}_{0.5} \mathrm{Mn}_{0.5}\right)_{2} \mathrm{GaC}$, skapas. Materialet analyserades och det visade sig att $\mathrm{Cr}$ och Mn finns fördelade slumpmässigt i varje $M$ lager. Andra egenskaper, bland annat magnetism, undersöktes. Med hjälp av teoretiska beräkningar föreslogs att MAX-fasen $\mathrm{Mn}_{2} \mathrm{GaC}$, ett material som aldrig skapats förut, borde vara stabil och borde kunna tas fram. Detta bevisades genom tunna filmer av just detta 
material. Materialets egenskaper analyserades noggrant, och komplicerade magnetiska egenskaper tillskrevs materialet.

Nyligen har det framkommit att det finns MAX-faser som består av två olika $M$ element, och där dessa element sitter ordnade $\mathrm{i}$ ett visst mönster. De är så kallade kemiskt ordnade MAX-faser. På samma sätt som teoretiska beräkningar kunde visa att $\mathrm{Mn}_{2} \mathrm{GaC}$ borde kunna tas fram, har beräkningar förutsagt nya ordnade MAX-faser med bland annat Mn som ett av atomslagen. Även dessa har jag lyckats skapa i labbet, vilket betyder rekord-höga nivåer av Mn-innehåll i en MAX-fas i bulk-form. Hur detta påverkar de magnetiska egenskaperna ska undersökas.

Magnetiska material är viktiga inom teknik för t.ex., datalagring. I denna avhandling har jag skapat och analyserat MAX-faser med Mn som har visat sig att ha intressanta magnetiska egenskaper. Detta arbete har gett inspirerande resultat för ytterligare framtida forskning av denna klass av material. 


\section{PrefaCe}

This Thesis summarizes my research done in Materials Design Group, Thin Film Physics Division, Department of Physics, Chemistry and Biology (IFM), Linköping University, Sweden between August 2011 and April 2018. I have primarily worked with synthesis of materials in both thin film form using magnetron sputtering and bulk form using pressureless sintering, as well as characterization of the synthesized materials. Part of the work presented herein has appeared in my licentiate thesis from October 2014, Synthesis and characterization of Ga-containing MAX phase thin films (Linköping Studies in Science and Technology, Licentiate thesis No. 1680).

The research was financially supported by European Research Council under the European Community Seventh Framework Program (FP7/2007-2013)/ERC Grant agreement No. 258509, and the Synergy Grant FUNCASE from the Swedish Foundation for Strategic Research

All calculations were carried out using supercomputer resources provided by the Swedish National Infrastructure for Computing (SNIC) at the National Supercomputer Centre (NSC) and High Performance Computing Centre North (HPC2N). 



\section{ACKNOWLEDGEMENTS}

I am very grateful to my supervisor Johanna Rosén for giving me a chance to be her graduate student and for all the guidance during my studies. I am also thankful to my co-supervisor Per Persson for sharing his knowledge in microscopy.

I would like to thank present and former member of Materials Design Group, especially Árni Sigurður Ingason, for showing me way around the lab, and Martin Dahlqvist for guiding me in theoretical calculations. Thanks to Aurelija Mockutè for being very helpful in the lab and reviewing written works. Thanks also to Rahele Meshkian, Chung-Chuan Lai and Igor Zhirkov for being great colleagues at work and awesome friends outside work. Thanks to all my co-authors and to all other colleagues in Thin Film Physics division who I have worked with. I want to also thank all my friends here in Linköping for making my stay here pleasant.

And last but not least, I am very thankful to my loving wife Lìga for motivating me, and to my daughter Signe, who fills my life with joy. 



\section{INCLUDED PAPERS AND AUTHOR'S CONTRIBUTION}

\section{Paper I}

Phase stability of $\mathrm{Cr}_{n+1} \mathrm{GaC}_{n} \mathrm{MAX}$ phases from first principles and $\mathrm{Cr}_{2} \mathrm{GaC}$ thin-film synthesis using magnetron sputtering from elemental targets

A. Petruhins, A. S. Ingason, M. Dahlqvist, A. Mockute, M. Junaid, J. Birch, J. Lu, L. Hultman, P. O. Å. Persson, and J. Rosen

Physica Status Solidi Rapid Research Letters 7 (11), 971-974 (2013)

I was involved in planning the experiments and the theoretical work, and performed all depositions, the XRD characterization, and ab initio calculations. I took part in the analysis of the TEM results, and wrote the paper.

\section{Paper II}

A nanolaminated magnetic phase: $\mathrm{Mn}_{2} \mathrm{GaC}$

A. S. Ingason, A. Petruhins, M. Dahlqvist, F. Magnus, A. Mockute, B. Alling, L. Hultman, I. A. Abrikosov, P. O. A. Persson and J. Rosen

Materials Research Letters, 2 (2), 89-93 (2014)

I was involved in planning the experiments. I performed all depositions, I took part in the XRD characterization, and participated in the analysis of TEM, EDX, and VSM results. 


\section{Paper III}

Large uniaxial magnetostriction with sign inversion at the first order phase transition in the nanolaminated Mn2 GaC MAX phase

I. P. Novoselova, A. Petruhins, U. Wiedwald, A. S. Ingason, J. Palisaitis, T. Hase, M. Spasova, M. Farle, J. Rosen, and R. Salikhov

Scientific Reports, 8 (1), 2637 (2018)

I synthesized the samples and prepared them for the analysis. I took part in analysing the results and took part in writing the paper.

\section{Paper IV}

Synthesis and characterization of magnetic $\left(\mathrm{Cr}_{0.5} \mathrm{Mn}_{0.5}\right)_{2} \mathrm{GaC}$ thin films

A. Petruhins, A. S. Ingason, J. Lu, F. Magnus, S. Olafsson, and J. Rosen

Journal of Materials Science, 50 (13), 4495-4502 (2015)

I planned and performed all depositions, and the XRD and XRR characterization. I participated in the analysis of TEM, EDX and VSM results, and wrote the paper.

\section{Paper V}

Magnetic anisotropy in the (Cr0.5Mn0.5) 2 GaC MAX phase

R. Salikhov, A. S. Semisalova, A. Petruhins, A. S. Ingason, J. Rosen, U. Wiedwald, and M. Farle Materials Research Letters 3 (3), 156-160 (2015)

I synthesized the samples and prepared them for analysis. I took part in writing the paper. 


\section{Paper VI}

Toward structural optimization of MAX phases as epitaxial thin films

A. S. Ingason, A. Petruhins, and J. Rosen

Materials Research Letters 4 (3), 152-160, (2016)

I took part in developing and testing the theoretical model, and I performed synthesis and characterization on many of the films used in the publication.

\section{Paper VII}

Theoretical prediction and experimental verification of chemically ordered atomic laminates $\left(\mathrm{Cr}_{2 / 3} \mathrm{Sc}_{1 / 3}\right)_{2} \mathrm{GaC}$ and $\left(\mathrm{Mn}_{2 / 3} \mathrm{Sc}_{1 / 3}\right)_{2} \mathrm{GaC}(i$-MAX phases)

A. Petruhins, M. Dahlqvist, J. Lu, L. Hultman, and J. Rosen

In manuscript

I planned the experiments, performed all materials synthesis and XRD characterization and wrote the paper. 



\section{RELATED PAPERS}

Effect of Ti-Al cathode composition on plasma generation and plasma transport in direct current vacuum arc

I. Zhirkov, A. O. Eriksson, A. Petruhins, M. Dahlqvist, A. S. Ingason, and J. Rosén Journal of Applied Physics 115 (12), 123301, (2014)

Theoretical stability, thin film synthesis and transport properties of the $\mathrm{Mon}_{n+1} \mathrm{GaC}_{n}$ MAX phase

R. Meshkian, A. S. Ingason, M. Dahlqvist, A. Petruhins, U. B. Arnalds, F. Magnus, J. Lu, J. Rosen physica status solidi (RRL)-Rapid Research Letters 9 (3), 197-201, (2015)

Vacuum arc plasma generation and thin film deposition from a $\mathrm{TiB}_{2}$ cathode

I. Zhirkov, A. Petruhins, L. A. Naslund, S. Kolozsvári, P. Polcik, and J. Rosen

Applied Physics Letters 107 (18), 184103, (2015)

Effect of cathode composition and nitrogen pressure on macroparticle generation and type of arc discharge in a $\mathrm{DC}$ arc source with $\mathrm{Ti}-\mathrm{Al}$ compound cathodes

I. Zhirkov, A. Petruhins, and J. Rosén

Surface and Coatings Technology 281, 20-26, (2015) 
Magnetically driven anisotropic structural changes in the atomic laminate $\mathrm{Mn}_{2} \mathrm{GaC}$

M. Dahlqvist, A. S. Ingason, B. Alling, F. Magnus, A. Thore, A. Petruhins, A. Mockute, U. B. Arnalds, M. Sahlberg, B. Hjörvarsson, I. A. Abrikosov, and J. Rosen

Physical Review B 93 (1), 014410, (2016)

Generation of super-size macroparticles in a direct current vacuum arc discharge from a Mo-Cu cathode

I. Zhirkov, A. Petruhins, P. Polcik, S. Kolozsvári, and J. Rosen

Applied Physics Letters 108 (5), 054103, (2016)

Thermally induced substitutional reaction of $\mathrm{Fe}$ into $\mathrm{Mo2} \mathrm{GaC}$ thin films

C. C. Lai, A. Petruhins, J. Lu, M. Farle, L. Hultman, P. Eklund, and J. Rosen

Materials Research Letters 5, 533, (2017).

$\mathrm{Mn}_{3} \mathrm{GaC}$ inverse perovskite thin films by magnetron sputtering from elemental targets

A. Petruhins, A. S. Ingason, S. Olafsson, and J. Rosen

In manuscript 


\section{TABLE OF CONTENTS}

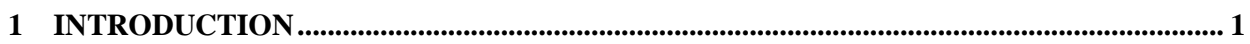

2 MAX PHASES

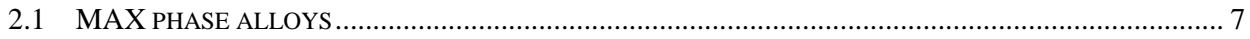

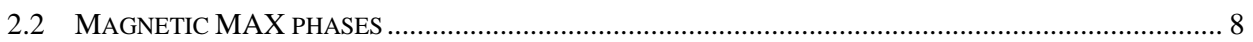

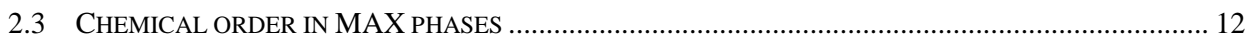

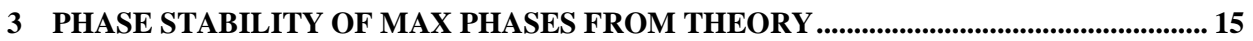

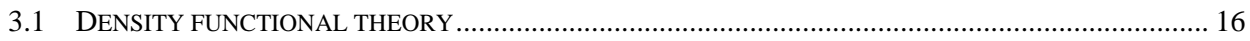

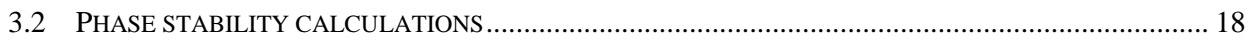

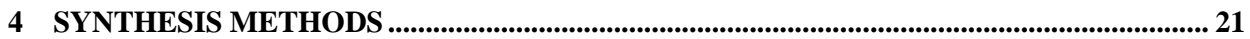

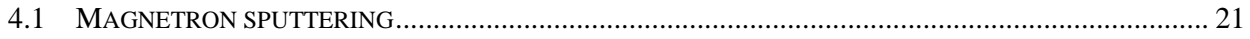

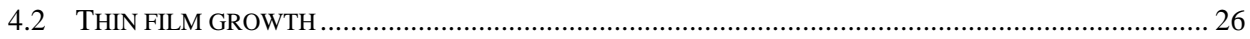

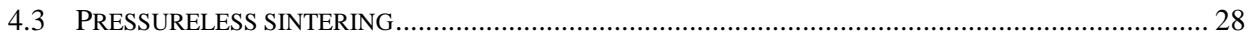

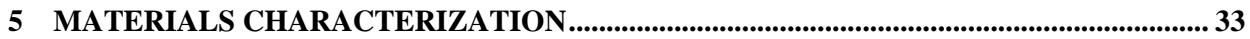

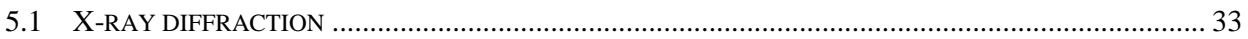

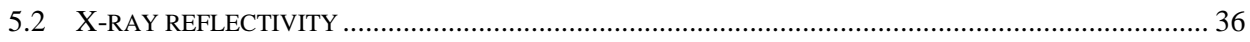

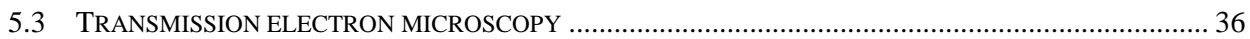

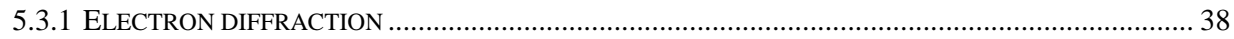

5.3.2 ENERGY DISPERSIVE X-RAY SPECTROSCOPY ............................................................ 39

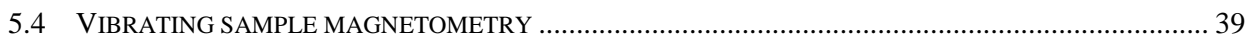

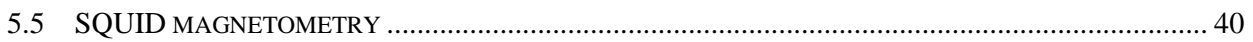

5.6 FERROMAGNETIC RESONANCE SPECTROSCOPY ......................................................... 41

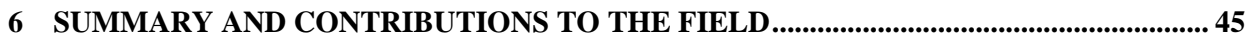

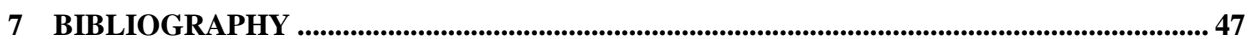





\section{1}

\section{INTRODUCTION}

Materials science is an interdisciplinary field comprising studies of materials and their properties, as well as discovery and design of new materials. Materials studies involve characterization of structure, composition, properties and performance, thus allowing feedback to the synthesis process aiming for specific tailor-made materials. This scientific field is driven by an increasing demand on the materials' properties and performance, originating from a rapid development of new technologies. Implementation of newer improved materials and processes by the industry creates added value for the society and the economy.

Thin films are thin layers of materials, typically $\mathrm{nm}-\mu \mathrm{m}$ range, that are encountered almost everywhere in the modern society. They are found, e.g., as metal coating on mirrors, anti-reflective coatings on eyewear, and as scratch-resistant protective coating on your smartphone screen. Thin films are used to change or add properties of a material or a device, for example, as a protective layer in hard coatings, or as an active part of a device, such as ferromagnetic coatings in a hard disk drive.

Magnetic materials have been known to humanity for a long time, and were used in compasses as early as $1000 \mathrm{BC}[1]$. Since then, the theory and understanding of magnetism has developed, and magnetic materials have found their way into numerous applications such as motors, hard disk drives, and medical imaging. However, technological advancements put demands on developing new and improved magnetic materials. In particular, layered magnetic materials have gained a lot of attention in the last decade. In 2007, the Nobel Prize in Physics was awarded to Albert Fert and Peter Grünberg for the discovery of giant magnetoresistance (GMR) in magnetic multilayers, a phenomenon that can be used for data storage and magnetic recording. As GMR is observed in multilayer structures, the applicability of different 
magnetic materials depends not only on magnetic properties, but also on structural quality, layer thickness, as well as interface quality.

MAX phases are a group of nanolaminated ternary carbides and nitrides, which chemical composition can be expressed with a general formula $M_{n+1} A X_{n}(n=1-3)$, where $M$ is a transition metal, $A-$ an A-group element, and $X$ is carbon or nitrogen [2,3]. Discovered already in the 1960s [4], they are atomic laminates that all share the same archetypical structure with very similar in-plane lattice parameters. Hence, they are potentially suitable for being stacked together with close to perfect interfaces, and therefore these materials could potentially be suitable for GMR applications, if endowed with suitable magnetic properties. They are inherently nanolaminated, suggesting anisotropic properties [5]. The characteristic layered structure for $M_{2} A X(n=1)$ is shown in Figure 1.1.

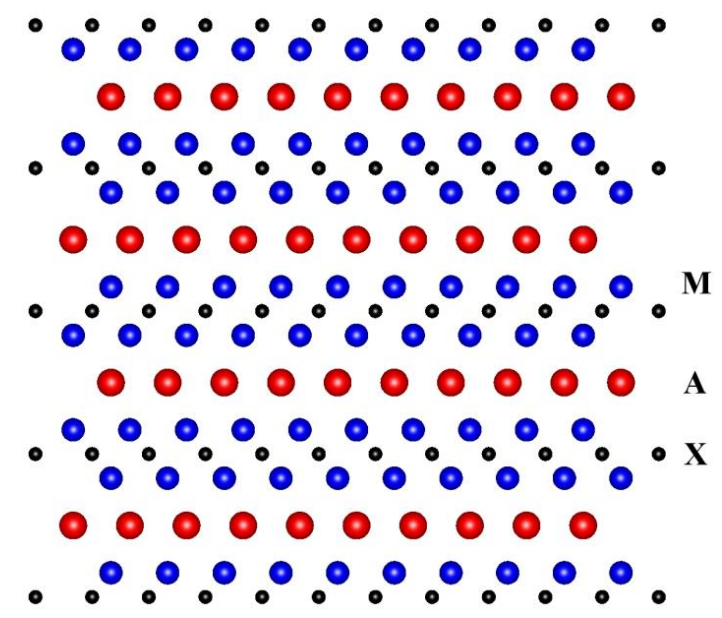

Figure 1.1. Nanolaminated structure of $M_{2} A X$ with $M_{2} X$ interleaved by layers of $A$ atoms, as viewed from from [112̄0] direction.

In the case of $M_{2} A X$, the structure consists of $M-X-M\left(M_{2} X\right)$ slabs interleaved by an $A$-element layer and these layers are stacked along the $c$-axis. Owing to the laminated structure, these materials exhibit a unique combination of ceramic and metallic properties; ceramic - e.g. damage tolerance, high stiffness, chemical stability, resistance to corrosion and thermal shock, and metallic - good electric and thermal conductivity [6]. The chemical bonding in MAX phases is a combination of metallic, ionic and covalent [7]. Since 2013, magnetic properties [8] are also among those associated with some of these materials. 


\section{CHAPTER 1 - INTRODUCTION}

Although many MAX phases have been synthesized in thin film form, most commonly by a method called magnetron sputtering, not all the MAX phase elements are straightforward to deposit. For example, Ga has a melting point of $30{ }^{\circ} \mathrm{C}$, and thus the Ga target will become liquid during deposition. This introduces several challenges for a well-controlled thin film synthesis process. However, $\mathrm{Ga}$ is a highly interesting element for development of novel magnetic MAX phases, as predicted by theoretical calculations.

The scope of this Thesis is to explore the fundamentals of magnetic MAX phases and related hybrid phases in their thin film and bulk form. This is motivated by their laminated structure, which the whole group of materials share, and a possible future synthesis of superstructures with highly controlled interfaces. A prerequisite for such investigations is development of synthesis processes that allows thin film growth of materials with very high structural and compositional quality (Paper VI). In this Thesis, this has been achieved by a project on reproducible materials synthesis and process development for sputtering from a liquid target, using $\mathrm{Cr}_{2} \mathrm{GaC}$ MAX phase as a proof-of-concept material (Paper I).

Guided by $a b$ initio calculations, successful thin film growth of $\mathrm{Mn}_{2} \mathrm{GaC}$ was performed, which was the first time a MAX phase with $\mathrm{Mn}$ as a sole $M$-element was synthesized. Its structural and magnetic properties were investigated (Paper II). A follow-up study investigated magnetic properties, including magnetization and determination of Neél temperature, magnetoresistance, magnetostriction and magnetocaloric effects of this material (Paper III).

Once the synthesis procedures are established, and the ternary $\mathrm{Cr}_{2} \mathrm{GaC}$ and $\mathrm{Mn}_{2} \mathrm{GaC}$ are realized in thin film form, attention is turned towards magnetic MAX phases from alloying $\mathrm{Cr}_{2} \mathrm{GaC}$ with $\mathrm{Mn}$, to attain a $\left(\mathrm{Cr}_{0.5} \mathrm{Mn}_{0.5}\right)_{2} \mathrm{GaC}$ thin films. The crystal structure and structural quality was studied, along with composition and magnetic properties (Papers IV and V).

There are no reports to date on $\mathrm{Mn}_{2} \mathrm{GaC}$ synthesis in bulk form, and there are indications that the Mn solubility in bulk MAX phase alloys is lower than for corresponding thin films [9]. In this Thesis, the Mn content in a bulk MAX phase has been increased through theoretical prediction and experimental verification (bulk synthesis using pressureless sintering) of a Mn-based so called $i$-MAX phase [10,11], which is a chemically ordered quaternary MAX phase with two $M$-elements in a 2:1 ratio (Paper VII). The effect of the increase in $\mathrm{Mn}$ content and the chemical order is the topic of future investigations. 



\section{2}

\section{MAX PHASES}

MAX phases were first discovered in the 1960's by Nowotny [12], when studying "TMX" phases of the general formula $T_{x} M_{y} X_{z}$, where $T$ is transition metal, $M$ is group 12-16 metal or another transition metal and $X$ is $\mathrm{C}$ or $\mathrm{N}$. More than 100 new carbides and nitrides were discovered then, and about 40 of them were ternary carbides of the general formula $M_{n+1} A X_{n}$ ( $n=1-3)$ that are today known as MAX phases. However, it was not until the 1990's that scientific interest in these materials was reignited after demonstrating the unique combination of metallic and ceramic properties in a phase pure bulk sample of $\mathrm{Ti}_{3} \mathrm{SiC}_{2}$ [13]. Today, more than 70 MAX phases exist, and Figure 2.1 shows the elements in the periodic table that form the $M_{n+1} A X_{n}$ phases known to date.

In 2002, an epitaxial thin film of a MAX phase, $\mathrm{Ti}_{3} \mathrm{SiC}_{2}$, was synthesized for the first time [14]. Thin film growth of MAX phases allows highly oriented crystalline material for detailed characterization of properties. Since then, many MAX phases previously synthesized as bulk material only have been synthesized also in thin film form, in addition to more recently discovered MAX phases which to this date have been reported only as thin films [1517].

In the last decade, the MAX phase research field has evolved primarily towards graphene-like 2D structures derived from MAX phases, the so called MXenes [18], but also towards more in-depth studies of MAX phase properties such as mechanical [19], electrical [20], tribological [21], optical [22] and more recently magnetic properties [23-25]. 


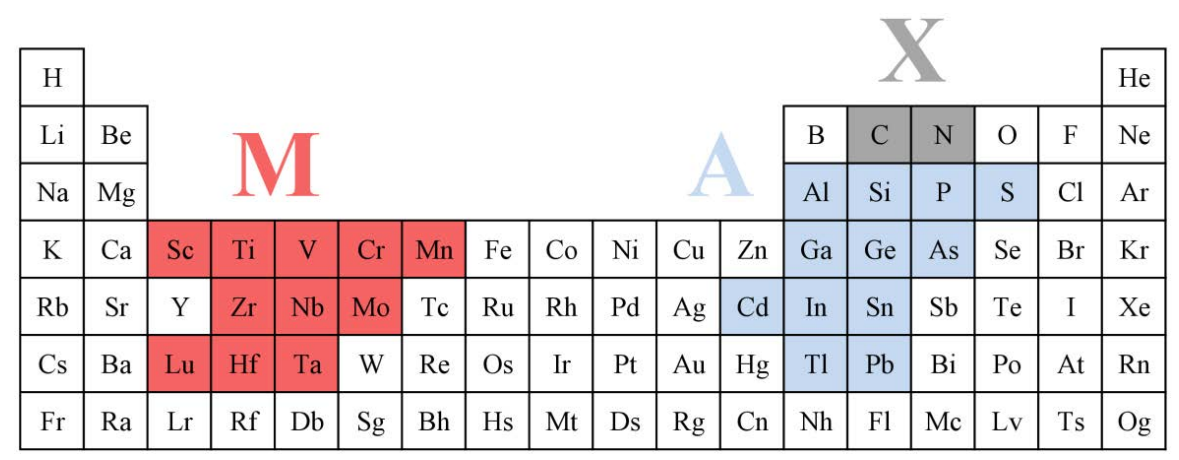

Figure 2.1. Periodic table with the $M, A$, and $X$ elements forming all $M_{n+1} A X_{n}$ phases known to date.

MAX phases share a hexagonal structure (space group $\mathrm{P}_{3} / m m c$ ), in which edge sharing $M_{6} X$ octahedra are interleaved by layers of the $A$-element, hence forming a naturally nanolaminated material. Different stoichiometries of $M_{2} A X, M_{3} A X_{2}$ and $M_{4} A X_{3}$ are referred to as 211, 312 and 413, respectively. Unit cells of 211, 312, and 413 MAX phases can be seen in Figure 2.2. It was recently discovered, that there exists a related phase with $2 A$ layers, the so called 221 phase $\mathrm{Mo}_{2} \mathrm{Ga}_{2} \mathrm{C}$ [26,27], which exhibit structural similarities to the MAX phases.

More complex related stoichiometries have also been observed, such as 514 [28], 615 [29], and 716 [30], as well as hybrid intergrown stoichiometries of 523 [15], interpreted as alternating layers of 211 and 312, and 725 [15], interpreted as alternating layers of 413 and 312. These complex stoichiometries are, however, not regarded as members of the MAX phase family, since they have been observed merely as minute grains or short stacking sequences within a more common MAX phase structure.

Since all MAX phases are closely related with respect to structure and composition, similarities in their properties are also observed, such as being machinable [3], having good electrical and thermal conductivity [13] as well as excellent damage and thermal shock tolerance [31]. Selected MAX phases have also demonstrated high temperature oxidation resistance [32] and self-healing properties [33,34].

MAX phases are promising for various applications. For example, $\mathrm{Ti}_{2} \mathrm{AlC}$, branded under the tradename Maxthal ${ }^{\circledR} 211$ by Kanthal ${ }^{\circledR}$, can be used for high temperature heating elements and gas burner nozzles, offering better properties than conventional metals, especially in corrosive environments. Kanthal ${ }^{\circledR}$ also manufactures $\mathrm{Ti}_{3} \mathrm{SiC}_{2}$ MAX phase under 
the tradename Maxthal ${ }^{\circledR}$ 312, which can be used for both low and high current electrical contact applications, owing to high ductility, chemical inertness and low contact resistance of the material. Among potential applications for MAX phases are as a materials with neutron irradiation resistance for nuclear reactor parts[35]. MAX phases are also extensively used as a precursor for synthesizing their 2D counterparts - MXene [18]. The family of MXenes itself has expanded rapidly in recent years and is promising for various applications including energy storage [36] and electromagnetic shielding [37].

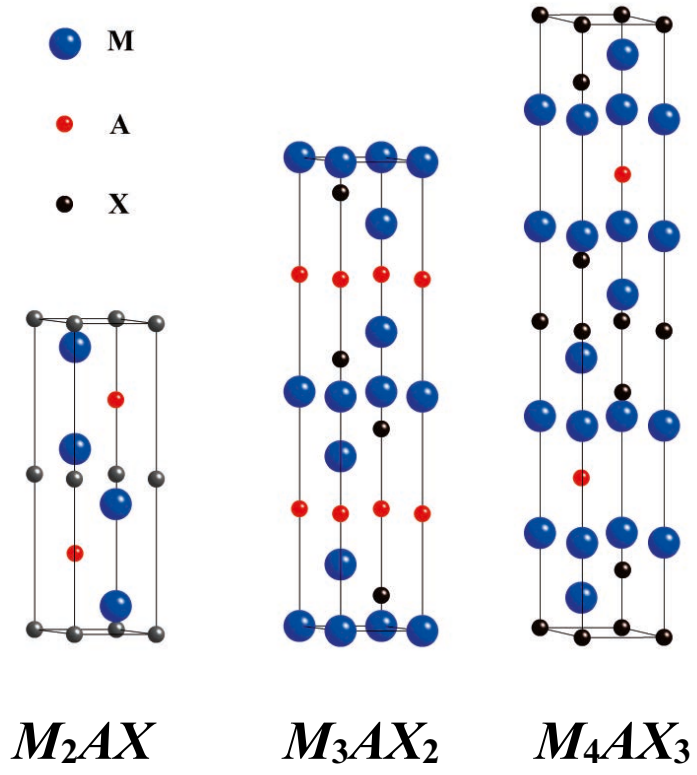

Figure 2.2. Unit cells of $M_{2} A X(211), M_{3} A X_{2}$ (312) and $M_{4} A X_{3}$ (413) phases.

\subsection{MAX phase alloys}

As MAX phases are formed from neighbouring elements in the periodic table, there is a great opportunity for alloying into isostructural solid solutions on $M, A$ and $X$ sites. Such alloys have been extensively studied, e.g., $(\mathrm{Nb}, \mathrm{V})_{2} \mathrm{AlC}$ [38], $\mathrm{Cr}_{2}(\mathrm{Al}, \mathrm{Ge}) \mathrm{C}$ [39], and $\mathrm{Ti}_{2} \mathrm{Al}(\mathrm{C}, \mathrm{N})$ [40]. Alloying on $M$ and $A$ sites has been most studied due to a larger number of attainable elemental combinations, while studies on $X$ site alloying are limited due to the two elements only available. However, experimental observations have suggested a significant amount of oxygen substitution on the $X$ site while retaining the MAX phase structure $[41,42]$. These observations were later supported by ab initio calculations $[5,43]$ indicating possible tuning of 


\section{CHAPTER 2 - MAX PHASES}

the material properties with change in oxygen content. Oxygen incorporation as interstitials was later also studied both theoretically and experimentally for $\mathrm{Cr}_{2} \mathrm{AlC}$ [44].

Substitution of one element with another gives the opportunity to tune the material properties, by adjusting the amount of the element substituted. The material properties in solid solutions can change in monotonous manner, e.g. the thermal expansion of $\mathrm{Cr}_{2} \mathrm{AlC}$ changes linearly when substituting $\mathrm{Al}$ with $\mathrm{Ge}$ throughout the whole composition range of $\mathrm{Cr}_{2}(\mathrm{Al}, \mathrm{Ge}) \mathrm{C}$ [39]. However, alloying can also give rise to properties that are superior compared to the pure MAX phase constituents, for example, the $\mathrm{Ti}_{2} \mathrm{AlC}_{0.5} \mathrm{~N}_{0.5}$ solid solution exhibits approx. 20\% higher hardness than $\mathrm{Ti}_{2} \mathrm{AlC}$ and almost $30 \%$ higher than $\mathrm{Ti}_{2} \mathrm{AlN}$ [40].

Synthesis of MAX phase solid solutions can also be a tool to expand MAX phases beyond known compositions, such as where the pure ternary forms of MAX phase exist, e.g. $\mathrm{Ti}_{3} \mathrm{GeC}_{2}$ and $\mathrm{Ti}_{4} \mathrm{GeC}_{3}$, and is used to stabilize new MAX phase alloys, such as $(\mathrm{Ti}, \mathrm{V})_{3} \mathrm{GeC}_{2}$ and $(\mathrm{Ti}, \mathrm{V})_{4} \mathrm{GeC}_{3}[45]$, where neither $\mathrm{V}_{3} \mathrm{GeC}_{2}$ nor $\mathrm{V}_{4} \mathrm{GeC}_{3}$ exist in pure form. It could also be pointed out that the aforementioned unconventional MAX phase stoichiometry of 514 was synthesized as a solid solution between $\mathrm{Ti}$ and $\mathrm{Nb}$ in $\left(\mathrm{Ti}_{0.5} \mathrm{Nb}_{0.5}\right)_{5} \mathrm{AlC}_{4}$ [28], whereas no other 514 MAX phase is known to exist up to date, demonstrating that solid solutions is indeed a way to expand the limits of known MAX phases.

\subsection{Magnetic MAX phases}

Although Mn is marked as an element belonging to the MAX phase family in Figure 2.1., it was introduced only very recently. In 2010, a method for theoretically predicting the phase stability of MAX phases was established. This method was benchmarked and could reproduce experimental occurrences of a large set of known stable MAX phases [46]. Later, the same method was used for predicting the previously unknown $\mathrm{Nb}_{2} \mathrm{GeC}$ MAX phase, which was subsequently synthesized, and hence could demonstrate the predictive power of the method [47]. This result motivated a search for new MAX phases composed of new MAX phase elements.

MAX phases containing Mn have attracted a lot of attention in the research community by introducing a new property previously not associated with the MAX phase family magnetism. The initial search for a magnetic MAX phase did not include Mn, but rather focused on the more commonly recognized magnetic element $\mathrm{Fe}$, typically displaying ferromagnetism (FM). The hypothetical magnetic $\mathrm{Fe}_{n+1} A \mathrm{C}_{n}(n=1-3, A=\mathrm{Al}, \mathrm{Si}$, or $\mathrm{Ge})$ 


\section{CHAPTER 2 - MAX PHASES}

were theoretically investigated by Luo et al. [48], and the study suggested that $\mathrm{Fe}_{3} \mathrm{AlC}_{2}$ was stable and ferromagnetic with a magnetic moment of $0.73 \mu_{\mathrm{B}}$ per Fe atom. However, no Fe-Al-C MAX phases have been found experimentally. In a later theoretical study, the $\mathrm{Fe}_{3} \mathrm{AlC}_{2}$ MAX phase was found not stable, along with the other MAX phases in the Fe-Al-C system [49]. This explains the failed attempts for $\mathrm{Fe}_{3} \mathrm{AlC}_{2}$ materials synthesis. The latter study also explored the phase stability of $M_{n+1} \operatorname{AlC}_{\mathrm{n}}(n=1-3$ and $M=\mathrm{Cr}, \mathrm{Mn}, \mathrm{Fe}, \mathrm{Co})$. It was found that magnetic MAX phases based on $M=\mathrm{Mn}, \mathrm{Fe}$, and Co are unstable, however, $\left(\mathrm{Cr}_{1-x} \mathrm{Mn}_{x}\right)_{2} \mathrm{AlC}$ alloys were not only predicted to be stable at least up to $x=0.5$, they were also suggested to be ferromagnetically ordered. An experimental study on $\left(\mathrm{Cr}_{0.8} \mathrm{Mn}_{0.2}\right)_{2} \mathrm{AlC}$ revealed that corresponding thin films show magnetic response, with indication of a transition temperature well above room temperature [25]. Furthermore, $(\mathrm{Cr}, \mathrm{Mn})_{2} \mathrm{GeC}$ solid solutions were identified as theoretically stable, and successful synthesis of $\left(\mathrm{Cr}_{0.75} \mathrm{Mn}_{0.25}\right)_{2} \mathrm{GeC}$ thin films was thereafter reported [23]. The latter phase was the first MAX phase which was subject to evaluation of magnetism, and indeed displaying magnetic response, up to the maximum measurement temperature of $300 \mathrm{~K}$ [23]. At a temperature of $50 \mathrm{~K}$ the films had a saturation magnetic moment of $\mathrm{m}_{\mathrm{s}}=0.36 \mu_{\mathrm{B}}$ per $\mathrm{Mn}$ atom, with remanent moment $\mathrm{m}_{\mathrm{r}}=0.031 \mu_{\mathrm{B}}$. These numbers are smaller than those predicted from theory for FM ordering $\left(\mathrm{m}_{\mathrm{s}} \approx 2 \mu_{\mathrm{B}}\right.$ ), which could indicate competing magnetic interactions. This is not surprising as $\mathrm{Mn}$ is known to display complex magnetic ordering, such as chiral magnetic ordering in $\mathrm{Mn}$ monolayers [50].

(Cr, $\mathrm{Mn})_{2} \mathrm{AlC}$ and $(\mathrm{Cr}, \mathrm{Mn})_{2} \mathrm{GaC}$ solid solutions have also been studied in bulk form, and the results of this study suggest that the solubility of $\mathrm{Mn}$ in bulk $\mathrm{Cr}_{2} \mathrm{AlC}$ and $\mathrm{Cr}_{2} \mathrm{GaC}$ MAX phases is likely lower than in thin films [9]. Therefore, in the case of bulk synthesis, the ratios of the initial powder constituents cannot be used for stating the MAX phase composition. Similar results were also obtained for $\left(\mathrm{Cr}_{1-x} \mathrm{Mn}_{x}\right)_{2} \mathrm{GeC}$ solid solutions, where already at $x=0.1$ a noticeable amount of Mn containing impurity phases are formed, once again indicating the possibly of a lower solubility limit of $\mathrm{Mn}$ in the bulk material [51]. Claims of $\left(\mathrm{Cr}_{1-x} \mathrm{Mn}_{x}\right)_{2} \mathrm{GaC}$ solid solutions with $x$ up to 0.5 have been reported for a bulk material [52], however no compositional analysis was provided in the study.

These initial studies sparked follow-up studies, where several previously known MAX phase systems were alloyed with $\mathrm{Mn}$ for exploration of magnetic properties, resulting in $\left(\mathrm{Mo}_{0.5} \mathrm{Mn}_{0.5}\right)_{2} \mathrm{GaC}$ [53] and ( $\left.\mathrm{V}, \mathrm{Mn}\right)_{3} \mathrm{GaC}_{2}$ [54], which is the first Mn containing $312 \mathrm{MAX}$ phase. 


\section{CHAPTER 2 - MAX PHASES}

Perhaps the most important discovery of this Thesis was the new magnetic MAX phase $\mathrm{Mn}_{2} \mathrm{GaC}$. The phase was theoretically predicted, and experimentally verified through magnetron sputtering. The phase displayed a magnetic response interpreted as a non-collinear antiferromagnetic (AFM) as the ground state. A long range antiferromagnetic ordering in the structure was determined by neutron reflectometry [55]. The material exhibits two magnetic transitions: first order transition to collinear AFM at $214 \mathrm{~K}$ and thereafter to paramagnetic state at $507 \mathrm{~K}$. Its magnetic properties have been extensively studied [56]. Since both $\mathrm{Mn}_{2} \mathrm{GaC}$ and alloys of $(\mathrm{Cr}, \mathrm{Mn})_{2} A \mathrm{C}(A=\mathrm{Al}, \mathrm{Ge}, \mathrm{Ga})$ have been realized, it is fundamentally interesting to know the magnetic properties of the alloys, compared to the pure ternary counterparts, $\mathrm{Cr}_{2} A \mathrm{C}(A=\mathrm{Al}, \mathrm{Ge}, \mathrm{Ga})$.

Magnetic properties have been reported for the $\mathrm{Cr}_{2} A X$ (where $A=\mathrm{Al}, \mathrm{Ge}, \mathrm{Ga}$ and $X=\mathrm{C}$ or N) MAX phases. The results from these systems are usually inconclusive. $\mathrm{Cr}_{2} \mathrm{AlC}$ was studied using neutron scattering at low temperatures and a Curie temperature of $T_{c}=73 \mathrm{~K}$ was determined, with weak ferromagnetic ordering at lower temperatures, accompanied with insignificant thermal expansion, similar to that of Invar alloys [57]. They also determined the average magnetic moment to be $0.002 \mu$ B per $\mathrm{Cr}$ atom. In another study of thin films of $\mathrm{Cr}_{2} \mathrm{AlC}$ [58], similar behaviour was observed with small ferromagnetic signal present with $\mathrm{Cr}$ carrying the magnetic moment, which disappears above $100 \mathrm{~K}$. The magnetic moment determined from the X-ray magnetic circular dichroism (XMCD) was established to be $0.05 \mu_{\mathrm{B}}$ per $\mathrm{Cr}$ atom, larger than that of bulk sample, however the moments are significantly lower than predicted from theory [59]. The same study also investigated $\mathrm{Cr}_{2} \mathrm{GeC}$ thin films [58], obtaining $0.02 \mu_{\mathrm{B}}$ per $\mathrm{Cr}$ atom, however further magnetic measurements were suggested by the authors, to determine the magnetic ordering and possibly confirm the predicted AFM ordering from the theory [60-62].

From the magnetism point of view, $\mathrm{Cr}_{2} \mathrm{GaC}$ can be considered a Pauli paramagnet [63], thus a simple metal. This is essentially the only study where the magnetic properties of $\mathrm{Cr}_{2} \mathrm{GaC}$ were measured and yet it was not the main focus of the article, thus little effort has been placed in determining the magnetic ground state of $\mathrm{Cr}_{2} \mathrm{GaC}$. The main focus of this article was to determine the magnetic ground state of the $\mathrm{Cr}_{2} \mathrm{GaN}$ counterpart. Contrary to other carbides in the $\mathrm{Cr}$ related $\mathrm{Cr}_{2} A \mathrm{C}(A=\mathrm{Al}, \mathrm{Ga}, \mathrm{Ge})$ systems, the nitride $\mathrm{Cr}_{2} \mathrm{GaN}$ showed clearly different behaviour with the susceptibility being significantly higher than that of $\mathrm{Cr}_{2} \mathrm{GaC}$, as well as a magnetic transition at temperature of $170 \mathrm{~K}$, which was shown to be the spin-density wave transition at this temperature. 


\section{CHAPTER 2 - MAX PHASES}

Turning to the alloys, the report on bulk $\left(\mathrm{Cr}_{1-x} \mathrm{Mn}_{x}\right)_{2} \mathrm{AlC}$ and $\left(\mathrm{Cr}_{1-x} \mathrm{Mn}_{x}\right)_{2} \mathrm{GaC}$ [9] showed that the former did not exhibit magnetic response for a Mn content of only $x=0.06$ whereas the latter had a Mn content of $x=0.3$, revealing two magnetic transitions at $T_{t_{1}}=38 \mathrm{~K}$ and $T_{t_{2}}=153 \mathrm{~K}$. Another study on bulk $\left(\mathrm{Cr}_{1-x} \mathrm{Mn}_{x}\right)_{2} \mathrm{GaC}$ solid solutions with allegedly $x=0.5$, showed paramagnetic response with a weak ferrimagnetism at the ground state [52]. Furthermore, a report on bulk $\left(\mathrm{Cr}_{1-x} \mathrm{Mn}_{x}\right)_{2} \mathrm{GeC}$ solid solutions suggested the coexistence of ferromagnetic and re-entrant cluster glass state in the material [51]. Segregation of Mn into Mn-poor and Mn-rich regions was also suggested in the study. Hence, these materials systems needs to be revisited, for improvement of the sample quality as well as interpretation of the magnetic characteristics. To date, no systematic study of a step wise increase in Mn-concentration has been performed. Altogether, the field of magnetic MAX phases is very young, and further understanding and a more comprehensive picture of the detailed magnetic properties is required for the materials discovered to date.

In this Thesis, growth of Ga containing MAX phases has been demonstrated, enabling realization of $\mathrm{Cr}_{2} \mathrm{GaC}$, $\left(\mathrm{Cr}_{0.5} \mathrm{Mn}_{0.5}\right)_{2} \mathrm{GaC}$, and $\mathrm{Mn}_{2} \mathrm{GaC}$, for further exploration of magnetic properties. With the discovery of $\mathrm{Mn}_{2} \mathrm{GaC}$, a new element, $\mathrm{Mn}$, has been added to the MAX phase family.

A remaining outstanding quest in the field of magnetic MAX phases is incorporation of $\mathrm{Fe}, \mathrm{Co}$ and/or Ni. A few attempts have been reported, suggesting incorporation of Fe into the MAX phases $(\mathrm{Cr}, \mathrm{Fe})_{2} \mathrm{GeC}$ [64] and $(\mathrm{Cr}, \mathrm{Fe})_{2} \mathrm{AlC}$ [65]. However, both articles report incorporation of only few at. \% of Fe into the MAX phase structure, whereas the former lacks compositional analysis and relies merely on initial powder composition.

Thermally induced substitutional reaction, which is a relatively new method for synthesis of MAX phases, has also been used for introduction of Fe into the MAX phase structure. In a recent article, $\mathrm{Mo}_{2} \mathrm{GaC}$ was used as the initial MAX phase, with $\mathrm{Au}$ and $\mathrm{Fe}$ used for thermally induced substitution, which resulted in partial substitution of $\mathrm{Ga}$ for $\mathrm{Fe}$ and $\mathrm{Au}$ on the $A$ site of the MAX phase, and a final composition of the $A$-layer of about $\sim 50 \% \mathrm{Fe}$, $35 \% \mathrm{Ga}$, and $15 \% \mathrm{Au}[66]$. 


\subsection{Chemical order in MAX phases}

Reported solid solutions on either $M, A$ or $X$ sites in MAX phases have typically resulted in chemically disordered materials until recently, when chemical order was discovered in $\mathrm{Cr}_{2} \mathrm{TiAlC}_{2}[67,68]$. The paper presented a $M_{3} A X_{2}$ structure, though with out-of-plane chemical order through Ti layers sandwiched between Cr-C layers. Soon after that, several other chemically ordered nanolaminates were discovered: $\mathrm{TiMo}_{2} \mathrm{AlC}_{2}$ [69], $\mathrm{Ti}_{2} \mathrm{Mo}_{2} \mathrm{AlC}_{3}$ [70], $\mathrm{V}_{1.5} \mathrm{Cr}_{1.5} \mathrm{AlC}_{2}$ [71], $\mathrm{V}_{2.2} \mathrm{Cr}_{1.8} \mathrm{AlC}_{3}$ [71] and most recently $\mathrm{Mo}_{2} \mathrm{ScAlC}_{2}$ [72], all displaying outof-plane chemical order, thus the term $o$-MAX was coined [10]. It is worth noting that these aforementioned chemically ordered MAX phases exist only in $M_{3} A X_{2}$ and $M_{4} A X_{3}$ structures and have the same space group $\mathrm{P}_{3} / \mathrm{mmc}$ as previously reported MAX phases, see schematic representation the $o$-MAX phase structure in Figure 2.3.
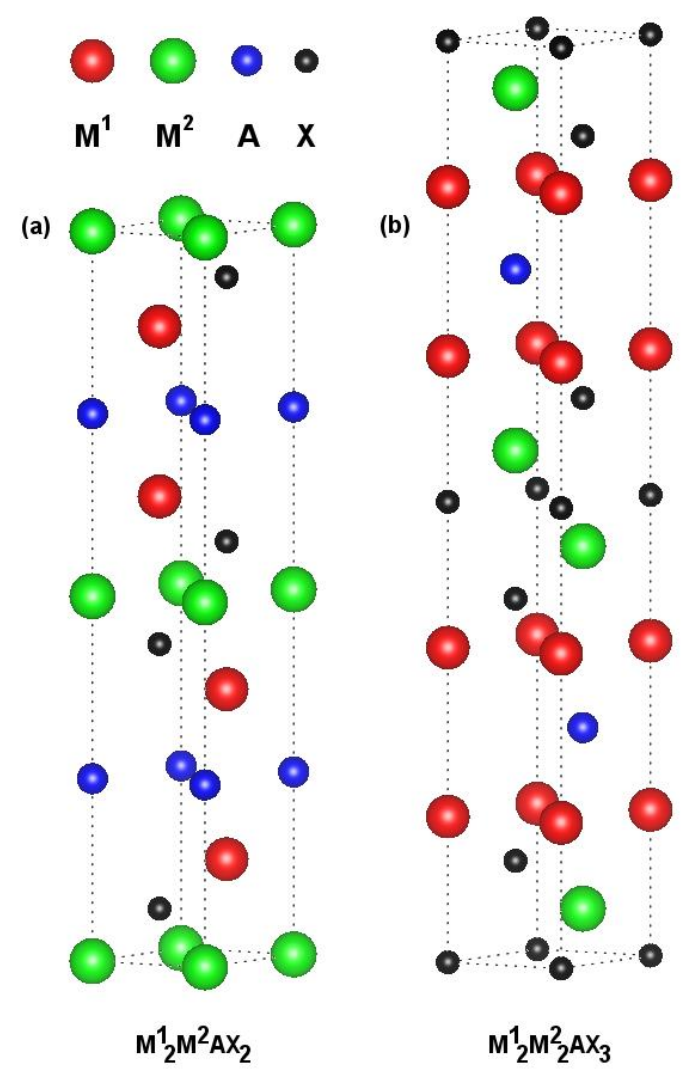

Figure 2.3. Unit cell schematic representations of out-of-plane ordered MAX phases $M_{2}^{1} M^{2} A X_{2}$ (a) and $M_{2}^{1} M_{2}^{2} A X_{3}$ (b). 


\section{CHAPTER 2 - MAX PHASES}

Further investigations on MAX phases and related materials resulted in discovery of $\left(\mathrm{Mo}_{2 / 3} \mathrm{Sc}_{1 / 3}\right)_{2} \mathrm{AlC}$ [11], which contrary to previously reported ordered MAX phases was a 211 phase, but in addition to that, it was discovered to have a different kind of chemical order. The $M$ sites were occupied by $\mathrm{Mo}$ and $\mathrm{Sc}$ in a ratio of 2:1, and the chemical order was in-plane, thus a term $i$-MAX was coined [10,11]. Also, the corresponding $2 \mathrm{D}$ derivative $\mathrm{Mo}_{1.33} \mathrm{C}$ MXene display chemical ordering, from selective etching of $\mathrm{Al}$ as well as Sc atoms, forming ordered divacancies in the MXene sheet. Soon afterwards, other $i$-MAX phases were also discovered, e.g. $\left(\mathrm{V}_{2 / 3} \mathrm{Zr}_{1 / 3}\right)_{2} \mathrm{AlC}$ and $\left(\mathrm{Mo}_{2 / 3} \mathrm{Y}_{1 / 3}\right)_{2} \mathrm{AlC}$ [73]. It is worth noting, that for the $i$-MAX phases, the structure does not belong to space group $\mathrm{P} 6_{3} / \mathrm{mmc}$ (194), as for the ternary MAX phases or the $o$-MAX, but rather they crystallize in a monoclinic $C 2 / c$ (15) or orthorhombic Cmcm (63) structure. A comparison between these two space group structures in different crystal orientations is shown in Figure 2.4.

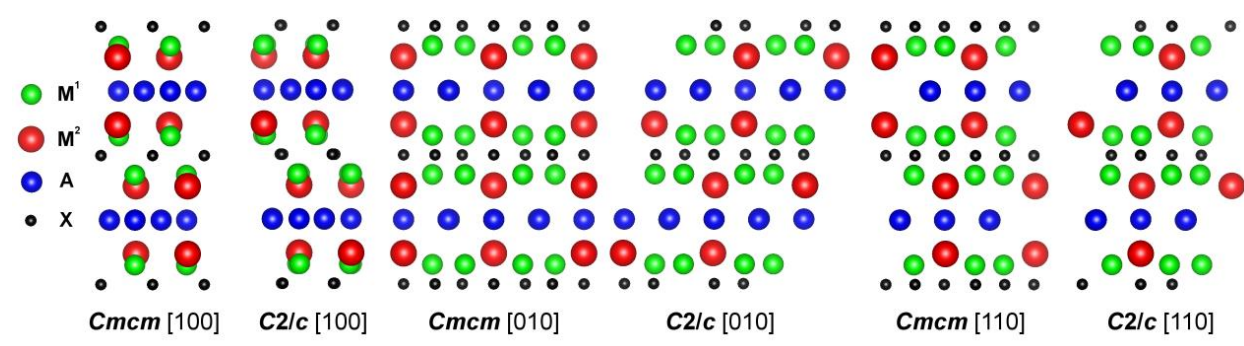

Figure 2.4. A schematic representation of a $\left(M_{2 / 3}^{1} M_{1 / 3}^{2}\right)_{2} A X i$-MAX in two different crystal structures belonging to space groups $C m c m(63)$ and $C 2 / c(15)$ as viewed along different zone axis. These different orientations will allow identification of the crystal structure when viewed in STEM.

The first $i$-MAX phases realized, all belonged to a group of phases with $A=\mathrm{Al}$. In this Thesis, which has a particular focus on MAX phases and related materials with $A=$ Ga, two new $i$-MAX phases, $\left(\mathrm{Cr}_{2 / 3} \mathrm{Sc}_{1 / 3}\right)_{2} \mathrm{GaC}$ and $\left(\mathrm{Mn}_{2 / 3} \mathrm{Sc}_{1 / 3}\right)_{2} \mathrm{GaC}$ have been theoretically predicted and experimentally verified. 



\section{3}

\section{PhASE STABILITY OF MAX PHASES FROM THEORY}

Evaluating the stability of a system or a material is usually associated with the minimization of the Gibbs free energy

$$
G=E+p V-T S
$$

where $E$ is the internal energy, $p$ is the pressure, $V$ is the volume, $T$ is the temperature and $S$ is entropy. Entropy can be considered as a measure of disorder, thus the TS term contributes only at finite temperatures $(T>0 \mathrm{~K})$, and with increasing $T$ disorder is energetically favoured.

When discussing the stability of a dynamic system, one should be aware of metastable states of the system. A metastable state corresponds to a local energy minimum, in which it can exist, until enough energy is supplied, to allow it to overcome its energy barrier, and eventually reach the global minimum - the ground state. This is illustrated in figure 3.1.

A system can have several local minima but only one global minimum. The energy that a certain system has to overcome (the barrier) to reach its ground state is called the activation energy. It can be understood as an energy that is necessary to initiate a reaction and/or start a phase transformation, from the initial state to the final one.

Studying the stability of MAX phases and determining if a hypothetical phase is stable or not, is important, since it can be efficiently used for guiding the experimentalists to avoid trial-and-error attempts of synthesis of unstable phases. Also, there are numerous publications [74-77] where $a b$ initio calculations have been used to calculate various properties of a hypothetical materials, yet they lack a discussion on the phase stability, thus raising the question of the value of doing substantial calculations on a material that cannot be realized experimentally. 
In this chapter, I will discuss the tools that we have used to determine the phase stability of MAX phases.

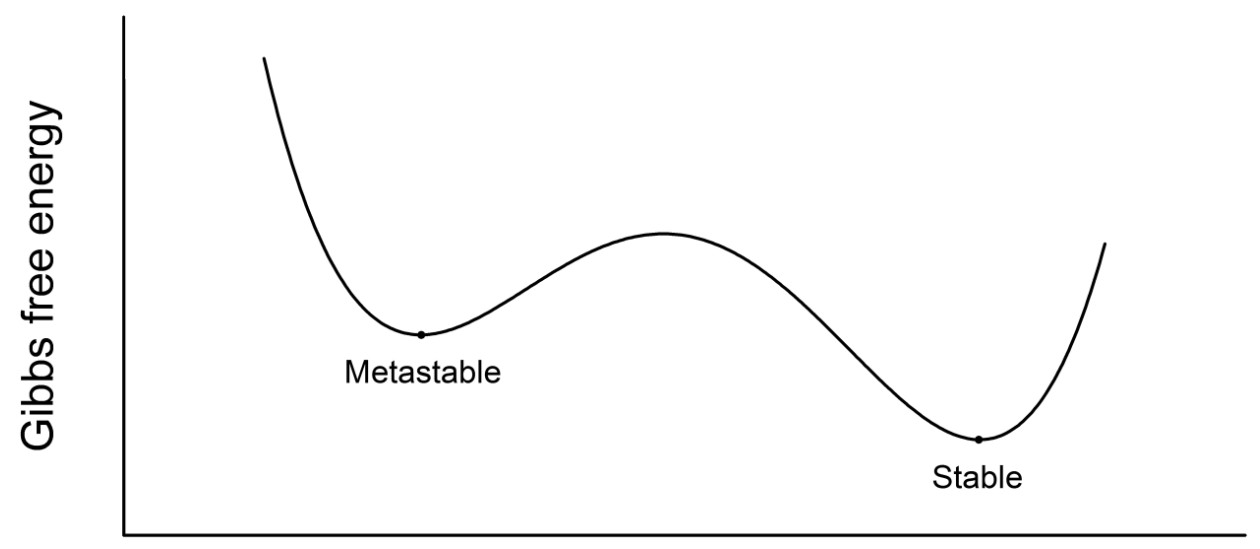

Figure 3.1. A hypothetical Gibbs free energy landscape that illustrates a metastable state (a local minimum) and the stable state of matter (the global minimum).

\subsection{Density functional theory}

When a theoretical method is described ab initio (Latin for "from the beginning") or from first-principles, it means that the theoretical calculations are done without any empirical data input. The problem is solved by finding a solution to the many body quantum mechanical equations. The complete Schrödinger equation of $\mathrm{N}$ electrons has $3 \mathrm{~N}$ degrees of freedom. The equation can be solved exactly for simple few-electron systems like the hydrogen or helium atom, which were the systems that allowed validation of the equation. However, for practically all other systems, it is too complex to be solved.

The main approach in density functional theory (DFT) is to approximate the electron density instead of individual $\mathrm{N}$ number of electrons. This method has proved very successful in describing various materials, ranging from atoms to even complex crystal systems. It is also computationally efficient, allowing evaluation of comparatively large systems with respect to various fundamental properties. DFT yields total energies, forces, and electronic structure and therefore allows computing of, e.g., structural relaxation and phase stability, energy differences (used as input for thermodynamics, kinetics, etc.), phonon dispersions (dynamical stability), property prediction and screening of such, and electronic band structures, but has its 


\section{CHAPTER 3 - PHASE STABILITY OF MAX PHASES FROM THEORY}

limitations, e.g., with respect to band gaps and optical properties (exciton states) and for strongly correlated systems.

The idea of approximating a number of electrons by a distribution was first considered by Thomas and Fermi in 1927 [78,79], but it received limited attention. It was almost 40 years later that the basis of the density functional theory was presented and applied practically by Hohenberg, Kohn, and Sham [80,81]

The Hohenberg-Kohn theorems [80] are the foundation of DFT. They state:

Theorem 1 states that for any system consisting of moving electrons in an external electric field $V_{\text {ext }}(\boldsymbol{r})$, this potential $V_{\text {ext }}(\boldsymbol{r})$ and thus the total energy is a unique functional of the ground state electron density $n_{0}(\boldsymbol{r})$.

Theorem 2 states that the ground state energy can be determined variationally, i.e. with the help of a functional, for any external potential $V_{\text {ext }}(\boldsymbol{r})$, the density $n(\boldsymbol{r})$ that minimizes the total energy is the exact ground state density $n_{0}(\boldsymbol{r})$.

In practice, this energy functional is not known, thus approximations are needed for practical application of the theory. An alternative approach was later proposed by Walter Kohn and Lu Jeu Sham [81], that allowed this theory to be implemented. The main idea is to substitute this real system of interacting particles in an external electric potential $V_{\text {ext }}(\boldsymbol{r})$ by an auxillary system of non-interacting particles in an effective electric potential $V_{\text {eff }}(\boldsymbol{r})$. This auxillary system of non-interactive particles still gives the same ground state density as the interacting system, yet it greatly facilitates the calculations.

The effective potential is expressed as a sum of the external potential, the electrondensity interaction, and the exchange-correlation functional. In the total energy functional it is therefore the exchange-correlation energy functional that cannot be calculated exactly, thus requires approximations.

In the original paper by Kohn-Sham, it was suggested to approximate the exchangecorrelation by treating solids as homogenous electron gas, an approximation which was called the local density approximation (LDA). This approximation works best for systems where the electron density varies slowly. However, for others where the electron density varies significantly, e.g. $3 d$ transition metals, using LDA is most likely not satisfactory and typically underestimates the lattice parameters. The most well-known failure of the LDA is the 
determination of the ground state of Fe, which is ferromagnetic bcc structure, whereas calculations using LDA give non-magnetic fcc structure as the ground state[82].

An improved approximation, that allows description of the systems with more rapidly changing electron densities, includes the density gradient, such as the generalized gradient approximation (GGA). There are several different GGA implementations available, Becke (B88) [83], Perdew and Wang (PW91) [84], and Perdew, Burke, and Ernzerhof (PBE) [85]. GGA was a significant improvement over LDA, since it allowed better description of $3 d$ transition metal systems.

The single-particle wavefunctions in the Kohn-Sham equations need to be approximated and since a crystal is a periodic structure it may seem appropriate to use a plane wave representation. It is, however, not suitable for describing the electrons that are close to the nucleus, so called core electrons. Thus, it is generally solved by using the frozen core approximation, where these core states are included only once in the beginning of the calculation. Such method is called the pseudopotential method[86]. Blöchl expanded this idea developing the projector-augmented wave (PAW) method, later improved by Kresse[87], which is now widely used in ab initio software packages. In this Thesis, PAW method was employed as implemented in the Vienna Ab initio Simulation Package (VASP) [87-90]

\subsection{Phase stability calculations}

The main principle for evaluating the stability of a material is to compare its energy with the energy of a balancing set of competing phases. Using the DFT calculations, it is possible to calculate the ground state energies of all the phases included in the evaluation, thus we can compare these energies. But since a material system, to which a $M_{n+1} A X_{n}$ phase belongs, can contain a very large number of competing phases, it is a question how the set of competing phases are chosen. It can be found in literature $[15,48,75,91,92]$ that in most cases, that the set of competing phases is hand-picked. It has been shown that such ad-hoc procedures can lead to errors, that can cause contradicting results, e.g. calculations suggesting that the nonexisting $\mathrm{Ti}_{2} \mathrm{SiC}$ is being stable and the first high-purity synthesized MAX phase $\mathrm{Ti}_{3} \mathrm{SiC}_{2}$ is unstable [91].

The phases included in evaluation of phase stability in this thesis are chosen through a very thorough procedure, including all experimentally known phases, as well as hypothetical phases that are known to exist in neighbouring systems (that may be stable but unknown in 


\section{CHAPTER 3 - PHASE STABILITY OF MAX PHASES FROM THEORY}

the system of interest). To avoid $a d-h o c$ procedures, a linear optimization procedure based on the simplex method is used to determine the linear combination of phases that gives the lowest energy at the composition of interest. For the elemental composition of $b^{M}, b^{A}, b^{X}$, the set of competing phases is found by solving the linear optimization problem in form

$$
\min E_{c p}\left(b^{M}, b^{A}, b^{X}\right)=\sum_{i=1}^{n} x_{i} E_{i}
$$

where $E_{i}$ is the compound $i$ energy, $x_{i}$ is the amount of compound $i$, and $E_{c p}$ is the energy that needs to be minimized. For a $M_{n+1} A X_{n}$ phase, additional constraints for $b^{M}, b^{A}$ and $b^{X}$ are applied as $n+1,1$ and $n$, respectively.

After the set of most competing phases is found, one can calculate the formation enthalpy per atom for the $M_{n+1} A X_{n}$ phase, given by the equation

$$
\Delta H_{c p}\left(M_{n+1} A X_{n}\right)=\frac{E_{0}\left(M_{n+1} A X_{n}\right)-E_{c p}^{0}}{2(n+1)}
$$

where $E_{0}\left(M_{n+1} A X_{n}\right)$ is the total energy of $M_{n+1} A X_{n}$ phase, $E_{c p}^{0}$ is the total energy of the set of most competing phases found by minimization procedure.

If the formation enthalpy is positive, the $M_{n+1} A X_{n}$ phase is less energetically favourable than the competing phases, thus concluded to not be thermodynamically stable, or metastable. If the formation enthalpy is negative, the $M_{n+1} A X_{n}$ phase is suggested to be stable.

For calculating the energy of the $M_{n+1} A X_{n}$ phase and competing phases, it is important to include relevant magnetic characteristics, when doing such calculations. For example, various magnetic spin configurations should be evaluated, since some magnetic configurations are more energetically favourable than others. It should be pointed out, that for the case of $\mathrm{Mn}_{2} \mathrm{GaC}$, including appropriate magnetic configurations in the calculations was crucial for the phase to be stable, opposite to non-magnetic configuration which was unstable with respect to the set of most competing phases. It has also been shown that including a relevant spin configuration can be crucial when performing calculations on properties, like bulk modulus [59].

The work process for determining the stability of a phase can be illustrated in a flowchart, shown in Figure 3.2. 


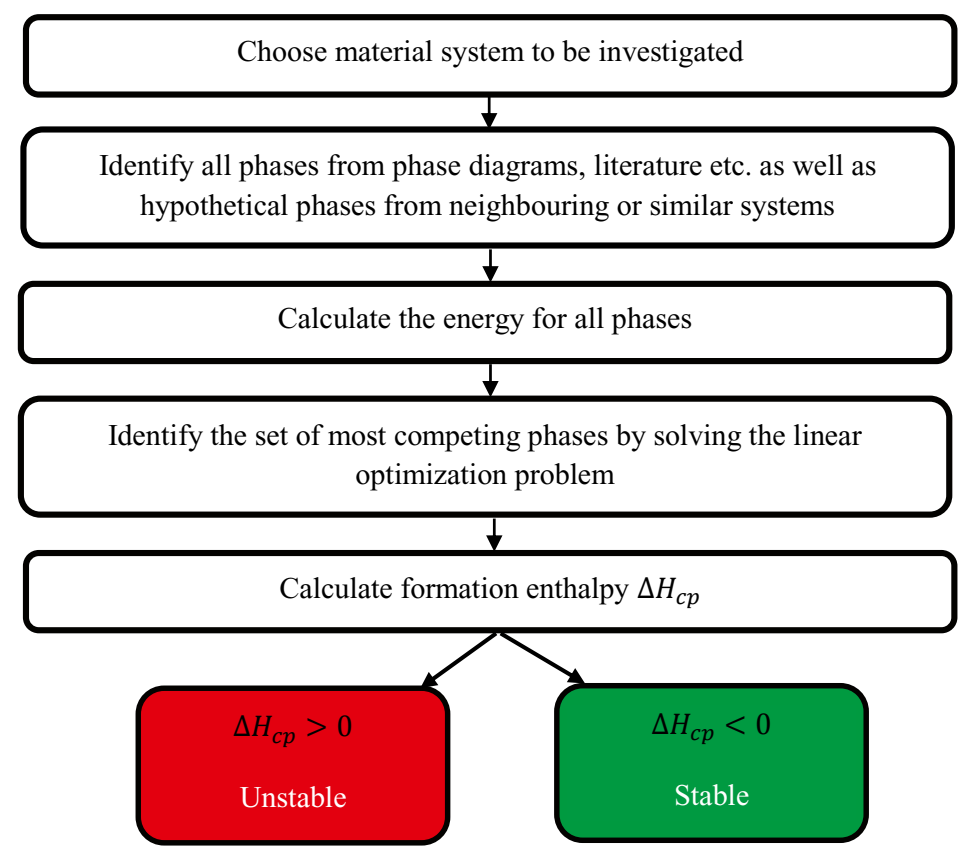

Figure 3.2. Flow chart showing the procedure for evaluation of phase stability.

This method has been successfully used in predicting new MAX phases, e.g., $\mathrm{Nb}_{2} \mathrm{GeC}$ [47], as well as $\mathrm{Mn}_{2} \mathrm{GaC}$ and the $i$-MAX phases $\left(\mathrm{Cr}_{2 / 3} \mathrm{Sc}_{1 / 3}\right)_{2} \mathrm{GaC}$ and $\left(\mathrm{Mn}_{2 / 3} \mathrm{Sc}_{1 / 3}\right)_{2} \mathrm{GaC}$, as demonstrated in this Thesis. 


\section{4}

\section{SYNTHESIS METHODS}

The synthesis of MAX phases and related materials can be performed as either thin films or in bulk form. The latter was performed in the 1960's [4] and the former was first demonstrated in 2004 [14]. Growth of thin films from vapour phase can be divided into two main groups: physical vapour deposition (PVD) and chemical vapour deposition (CVD). PVD employs purely physical processes, for example, thermal evaporation or magnetron sputtering, for generation of vapour which is condensed on a substrate. In CVD, the growth occurs through chemical reactions of species forming the desired material. The latter process takes place at thermodynamical equilibrium and thus requires high temperatures.

Numerous bulk synthesis techniques have been used for producing MAX phases, such as pressureless sintering [93], hot pressing [94], hot isostatic pressing (HIP) [95], self-propagating high-temperature synthesis (SHS) [96], pulse discharge sintering [97] and solid-liquid reaction synthesis [98].

In this thesis, magnetron sputtering and pressureless sintering has been used for materials synthesis, therefore these techniques are discussed in more detail below.

\subsection{Magnetron sputtering}

Sputtering is a process where ion bombardment of the target material causes ejection of atoms. Figure 4.1 shows a schematic drawing of a sputtering system. The system consists of a vacuum chamber inside which two electrodes are placed - a cathode and an anode. In a typical situation, one of the electrodes is omitted, since the chamber acts as an anode and the target, which is made of material to be deposited, is the cathode. The object that is to be 
coated (substrate) is placed in front of the target. An additional biasing voltage can be applied to the substrate or it can be at a floating potential.

An inert gas, typically Ar, is introduced into a vacuum chamber, and is ionized through collisions with other Ar atoms or secondary electrons. By applying a negative bias to the target, $\mathrm{Ar}^{+}$ions are accelerated towards that, colliding with the target material from which atoms are ejected (sputtered). The energy of these atoms is typically on the order of a few eV. The atoms are then transported to the substrate where they are deposited to form a film. Upon impact of $\mathrm{Ar}^{+}$ions with the target, secondary electrons are also created, which after collision with $\mathrm{Ar}$ atoms and ionize them creating more $\mathrm{Ar}^{+}$ions, which are attracted to the cathode, thus creating a self-sustaining plasma. The empirical condition to self-sustaining the plasma is $L \cdot p>0.5$ (cm·Torr), where $L$ is the spacing between electrodes (cathode-anode) and $p$ is the pressure.

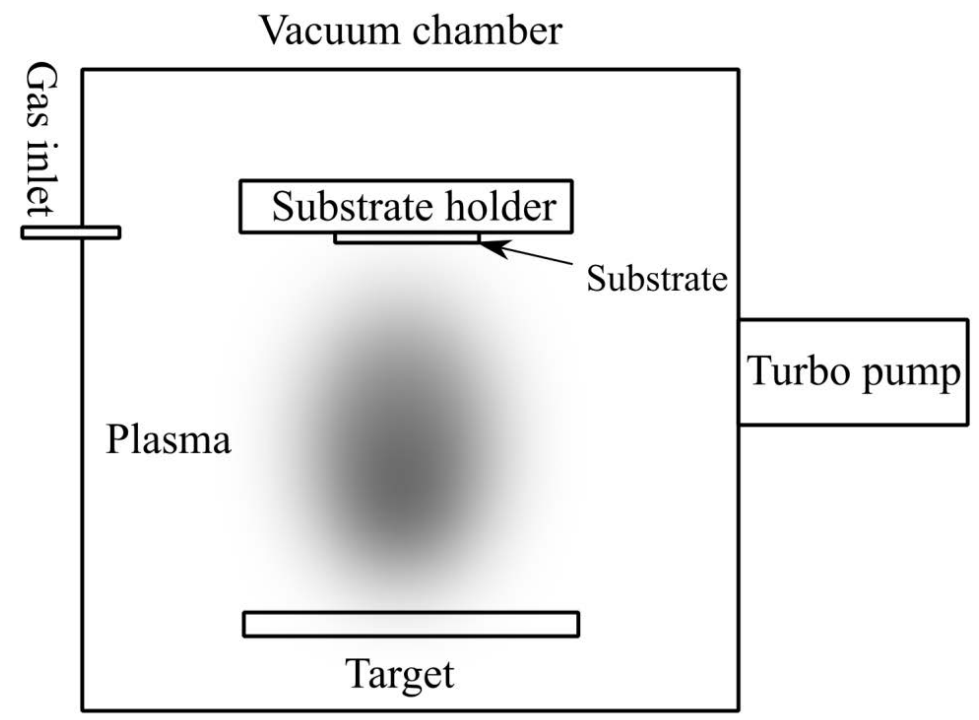

Figure 4.1. Basic schematic drawing of a sputtering system.

Upon ion impact with the target material, several possible interactions are possible. The ion can recoil from the material, it can be implanted inside the material, or create secondary electrons upon collision. The desired process is the ejection of target atoms, i.e. sputtering, which results from a collision cascade of the ion with the atoms in the topmost surface area (typically $\sim 5 \AA$ ). Different interactions between target and ion upon impact are illustrated in 
Figure 4.2. Sputtering yield is an average number of atoms sputtered from the material per incident ion and depends on the masses of the target atoms and incident ions, kinetic energy of incident ions, the heat of sublimation of the atoms at the target surface and the angle of incidence of incoming ions [99]. Sputtering yield calculation models give good agreement between calculated and experimental values [99] and the respective software packages employing these models are freely available [100].

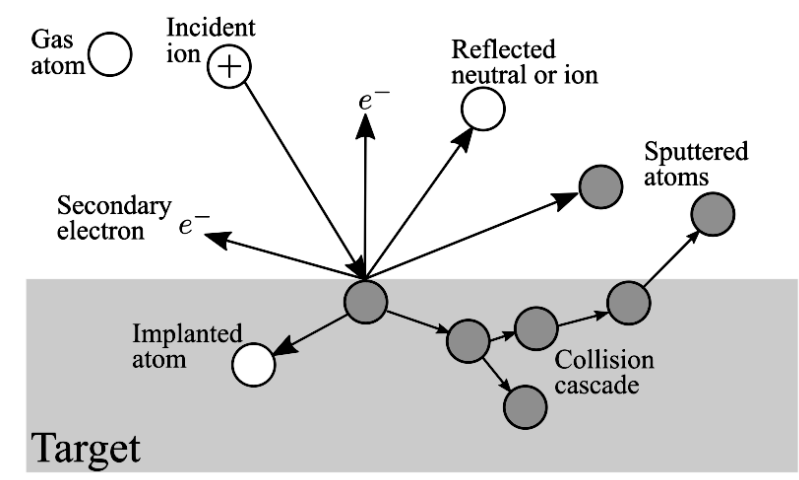

Figure 4.2. Processes that occur upon incident ion impact on the target.

After an atom has left the target surface and is travelling towards the substrate, it can collide with the particles in the vacuum chamber and be scattered [101]. The typical description of scattering is through the mean free path of a particle, which is the average distance the particle travels before it collides with another particle. The mean free path depends on pressure, temperature, as well as cross section and masses of the colliding particles. The sputtered atom travelling with certain kinetic energy loses part of its energy with every collision and after several collisions, all of its initial kinetic energy is lost. Such atom is said to be thermalized and is moving at random, similar to the motion of gas particles. For the pressure of 0.6 Pa, the mean free path is several $\mathrm{cm} \mathrm{[102],} \mathrm{which} \mathrm{is} \mathrm{on} \mathrm{the} \mathrm{order} \mathrm{of} \mathrm{the}$ distances used in typical vacuum chamber designs. Sputtering rate $R$ is in fact $R \propto \frac{1}{L \cdot p}$, where $L$ is the anode-cathode spacing, and $p$ is the working pressure. The pressure in the chamber can be varied to adjust so that the particles are travelling in a completely ballistic regime, thus arriving at the substrate surface with relatively high kinetic energy, increasing the adatom mobility on the surface, to the regime where particles are fully thermalized when reaching the substrate. Although it may seem that fully ballistic regime is more favourable from the point of view of nucleation and growth, it is often associated with low deposition rates and unstable 
plasmas, due to low number of gas species. On the other hand, high ambient pressure leads increased number of collision between target atoms and gas species, which prevents ionization of gas species.

In conventional sputtering, a high partial pressure of Ar is required for initiating a stable sputtering process. This is unfavourable due to a large amount of collisions of the target atoms on their way towards the substrate, where they lose energy and are scattered, which decreases the growth rate. Low energy of the species that arrive to the substrate can cause deterioration of the crystal quality of the film due to limited adatom mobility.

The basic concept of magnetron sputtering is placing magnets behind the target so that the magnetic field is applied parallel to the target surface and perpendicular to electric field. In this configuration, as a consequence of Lorentz force, the electrons will be confined close to the target surface and will hop in a cycloid pattern. Typically, the hopping radius is usually few $\mathrm{mm}$ long for electrons and several hundred times larger for $\mathrm{Ar}^{+}$ions, meaning that only the electrons are confined to the target surface and $\mathrm{Ar}^{+}$ions are mostly unaffected by the magnetic field. Confining electrons near the target surface significantly increases the amount of collisions with the Ar atoms, which consequently increases the degree of ionization. Two magnets are usually used, a circular one in the centre of the target and a toroidal more towards the periphery of the target. With this configuration, a region called the race-track can be defined, which is the region where the electrons hop around and consequently the gas is ionized the most. The sputtering is also the most efficient in this region, giving rise to a wellknown erosion section on the target surface. Usually, only about $25 \%$ of the target is utilized due to this erosion, being one of the main weaknesses of magnetron sputtering. There are developments of magnet configurations for improving the target material utilization, mainly for industrial systems.

Depending on the strengths of the inner and outer magnets, magnetron sputtering can be divided into balanced and unbalanced sputtering. All three different types of magnet configurations used in magnetron sputtering are illustrated in Figure 4.3. In the case of balanced or conventional magnetron sputtering, the strength of the inner and outer magnets is the same, meaning that the plasma is confined close (typically around $60 \mathrm{~mm}$ ) to the target surface [103]. This is usually used in cases when the substrate is placed close to the target, within the region where plasma is confined, however it is not always practical. If the strengths of the inner and outer magnets are different, such setup is called an unbalanced magnetron 
sputtering, which can in turn be divided into two possible ways - when inner magnets are stronger than outer (type I) or when outer magnets are stronger than inner magnets (type II). In the case of type I unbalanced magnetron sputtering, ion current density on the substrate is very low, compared to conventional sputtering, and thus this configuration is rarely used. It can be used to produce very porous and chemically reactive thin films [104]. The most commonly used is the type II unbalanced magnetron sputtering, which also is the one that was initially developed, despite misleading numbering of the types. In the case of type II unbalanced sputtering, the outer magnet is stronger than the inner, thus the magnetic field lines stretch out towards the substrate, also expanding the plasma away from the target and towards the substrate. Resulting ion current densities on the substrate are around an order of magnitude higher than that of conventional sputtering, as well as with a high flux of atoms, and thus being more efficient than conventional sputtering. This setup is indeed so popular that often type II is omitted and only unbalanced sputtering name is used.

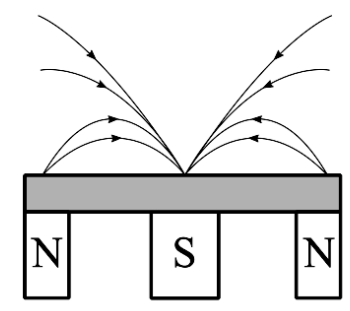

Unbalanced type I

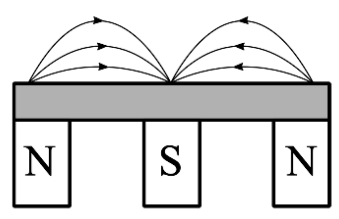

Balanced

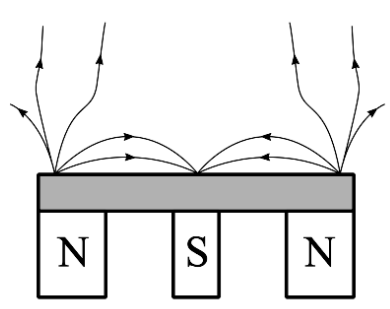

Unbalanced type II

Figure 4.3. Schematic representation of different magnet configurations used in magnetron sputtering.

Sputtering of a compound material can be done in several ways, most commonly:

1) Using a compound target.

2) Using elemental targets and a reactive gas (reactive sputtering).

3) Using elemental targets that form the compound composition.

In the case of sputtering from a compound target, several problems can arise, e.g., differences in angular and energy distributions of the sputtered species and scattered atoms, that result in films with different stoichiometry as compared to that of the target. In addition, deviations from the target stoichiometry in the film can arise from different sticking 
probabilities of the elements. For example, this has been reported for attempted synthesis of $\mathrm{Ti}_{3} \mathrm{SiC}_{2}$ thin films sputtered from a compound $\mathrm{Ti}_{3} \mathrm{SiC}_{2}$ target [105].

In reactive sputtering, the film is formed from a chemical reaction between the constituent target atoms and the gas. The film stoichiometry can be controlled by the partial pressures of the inert and the reactive gas. This method is used for deposition of nitrides [106], oxides [107], hydrides [108], fluorides [108], sulphides [109], borides [110], carbides [106], etc., and the method can be used for deposition of nitride MAX phase thin films, e.g., $\mathrm{Ti}_{2} \mathrm{AlN}[111]$.

When applicable, the use of elemental targets is often a preferred method for deposition of compounds, because it provides a higher degree of freedom allowing control of each of the elements independently. It is often the choice for growth of carbide MAX phase thin films, e.g. $\mathrm{Ti}_{3} \mathrm{SiC}_{2}$ [14]. Sometimes, due to constraints in the design of the deposition system, the number of available targets is below the number of elements forming the compound. In this case, two of the elements can be used in a binary compound target. For the case of pure MAX phase carbides, three targets are necessary to ensure the full degree of freedom for each of the constituting elements. However, when depositing MAX phase alloys either a four target deposition system needs to be used [24] or a compound target [23], where the former allows a larger variation of the alloy composition.

\subsection{Thin film growth}

After being sputtered, the species in the vapour phase are transported to the substrate where they condense and form a film. Atoms that arrive on the substrate are called adatoms. Typical kinetic energies of adatoms in magnetron sputtering are a few eV. Such energies can be sufficient for adatom diffusion on the surface, overcoming the Ehrlich-Schwoebel barrier to either find other adatoms, to form clusters or to be desorbed (evaporated). Formed clusters are not stable until they reach a critical nucleus size and continue to grow. Nucleation of grains is heterogeneous, which means that some sites are more energetically favourable than others. It is due to surface not being perfect and having defects, for example steps, that provide nucleation site with lower energy, allowing smaller critical nucleus size. By increasing the temperature, the number of these nucleation centres decreases, due to enhanced adatom mobility. 
The initial growth of film can be classified in three characteristic modes (Figure 4.4):

1. Frank-van der Merwe or layer-by-layer growth,

2. Stranski-Krastanov or layer-by-layer followed by island growth.

3. Volmer-Weber or island growth,

1.

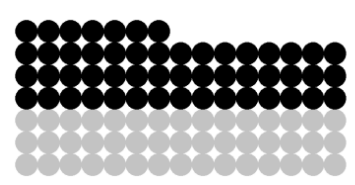

2.

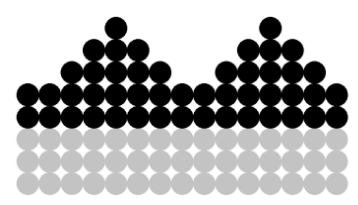

3.

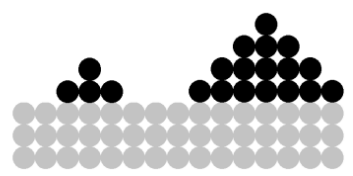

Figure 4.4. Thin film growth modes: 1. Layer-by-layer growth, 2. layer-by-layer followed by island growth, and 3. island growth.

By defining free energies of the surface $\left(\gamma_{S}\right)$, film $\left(\gamma_{F}\right)$ and interface $\left(\gamma_{I}\right)$, the preferred growth mode can be determined.

In the case of island or Volmer-Weber growth, the substrate free energy is lower than the sum of film and interface free energies $\gamma_{S}<\gamma_{F}+\gamma_{I}$. It means that atoms are more strongly bond to each other than they are to the substrate.

Frank-van der Merwe growth mechanism takes place when the substrate free energy is equal to the film free energy $\gamma_{S}=\gamma_{F}$, and it is possible only when a film is grown on a substrate of the chemically identical substrate, i.e., also called homoepitaxial film growth.

More commonly, a substrate and deposited film are chemically and crystallographically different, i.e. the case of heteroepitaxy. In the initial stages of growth, the condition for growth in terms of free energies can be described with the following inequality $\gamma_{S}>\gamma_{F}+\gamma_{I}$ which means that initially, the substrate free energy is higher than the sum of film and interface substrate energies, thus the films grows in a layer-by-layer fashion. It is usually possible when the respective lattice spacing difference is small between both crystals. However, since they are different, the grown film will be strained, which adds an additional free energy to the right-hand side of the inequality. As the film grows thicker, the strain energy increases and eventually becomes large enough to make layer-by-layer growth unfavourable and island growth will take over, which can be written in terms of free energy as 


$$
\gamma_{S}<\gamma_{F}+\gamma_{I}+\gamma_{\text {strain }}
$$

This growth mode is called Stranski-Krastanov.

Single crystals are often chosen as substrates, with specific atomic planes facing the plasma flux as incoming adatoms tend to diffuse to specific crystallographic sites on the substrate surface to minimizing the interfacial free energy. Such growth is called epitaxial growth. To achieve epitaxial growth of $(000 \ell)$ oriented MAX phases, single crystals of $\mathrm{Al}_{2} \mathrm{O}_{3}(0001), \mathrm{SiC}(0001)$, and $\mathrm{MgO}(111)$ are most commonly used.

Usually, a scientific publication on thin film synthesis includes information about the synthesis parameters, such as target composition, purity, size, orientation and distance to substrate, base and deposition pressures with gasses used, target sizes as well as parameters describing either applied power [112], current [105,113,114] or sometimes power density [115], which in turn can be directly related to power and target size. These parameters are those that are used for reproduction of given films. It is, however, difficult to relate to these given parameters, since each deposition system has its own unique design, thus the direct transfer of the knowledge between deposition systems is almost impossible. Sometimes, supposedly more elaborate description is given, for example, "The applied power on the sputtering targets was calibrated from known deposition rates and sputtering yields to result in a $\mathrm{Nb}: \mathrm{Ge}: \mathrm{C}$ composition of $2: 1: 1$.” [47] but without further explanation, this information is useless, as it is not clear what exactly does this really mean and how one should proceed with this information.

Therefore, a thin film deposition of previously known materials and especially of previously untackled materials often consists of numerous trial-and-error attempts until a desired high-quality sample is attained. However, finding the optimal deposition parameters can be very time consuming due to a large parameter space, especially for co-sputtering of several elemental targets. Identifying the most relevant parameters and providing sufficient information and guidance in the scientific reports is needed, so that a more rigid and reproducible way of depositing thin films can be established.

\subsection{Pressureless sintering}

Sintering is by definition a process where particles of a material are coalescing in a solid mass during heating without liquefaction [116]. Sintering has been known and employed for several 
thousands of years in pottery, where it was used as a part of firing process. Although known from ancient times, the sintering process was not investigated in detail, and it was only after the 1940s that the method was developed technologically. It became an important tool, most notably for fabrication of powder-metallurgical parts and ceramics.

Figure 4.5 shows the flowchart of a general sintering procedure.

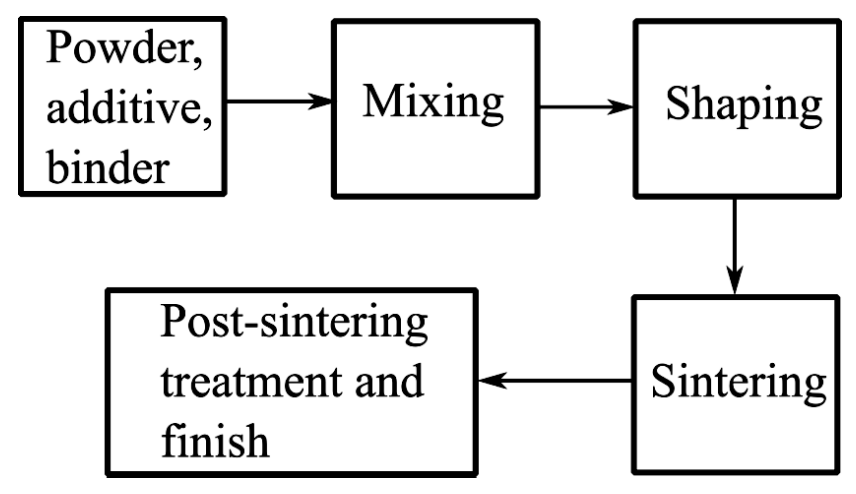

Figure 4.5. Flowchart of a general sintering procedure.

As seen from the Figure 4.5, the sintering procedure involves several parts, where each of them affect the end product. Therefore, there are many parameters that need to be taken into account for a controlled specific end result. For example, in the shaping part, several techniques, such as isostatic pressing or simple die compaction can be used.

Although the classic dictionary definition states that constituent materials do not melt during heating, nowadays the term sintering is generalized and is divided into two categories: solid phase sintering and liquid phase sintering. Solid state sintering is as per dictionary definition, where all constituents remain solid at the sintering temperature, whereas in the liquid phase sintering, a material in the liquid phase is present during sintering. Liquid phase sintering is usually used for materials that are difficult to sinter in solid phase, such as WC, where Co is added, forming the cemented carbide. Typically, the solid grains are soluble in the solution, thus this liquid phase helps to rearrange the grains due to capillary forces, helping densification, which is further achieved by high temperature as the solid phase becomes softer. Liquid phase is also associated with higher diffusion rates, allowing shorter sintering times or lowering the sintering temperatures. Liquid phase sintering is the main sintering process in commercial use [117]. 
Since sintering is an equilibrium process governed by laws of thermodynamics, its main driving force is the reduction of free energy. This reduction can be expressed as

$$
\Delta(\gamma A)=\Delta \gamma A+\gamma \Delta A
$$

where $\gamma$ is the specific surface energy and $A$ is the total surface area.

Specific surface energy change $\Delta \gamma$ is due to densification and the surface area change $\Delta \mathrm{A}$ is due to coarsening, which is illustrated in Figure 4.6. Thus the reduction of free energy is achieved by densification and grain growth, which are the basis processes during sintering.

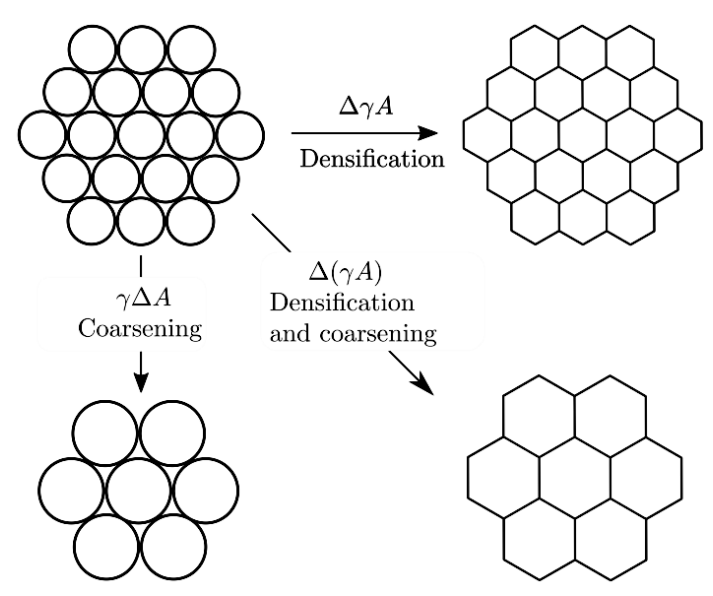

Figure 4.6. The schematic illustrating coarsening and densification.

If the governing process is densification, the compact is becomes more dense, however if the coarsening process is faster, the particles grow larger but so does also the pores.

For densification to occur, the grain boundary energy $\gamma_{b}$ needs to be less than twice the solid-vapour surface energy $\gamma_{\alpha \beta}$ and that the equilibrium dihedral angle (see Figure 4.7.) has to be less than $180^{\circ}$.

$$
\gamma_{b}=2 \gamma_{\alpha \beta} \cos \frac{\phi}{2}
$$




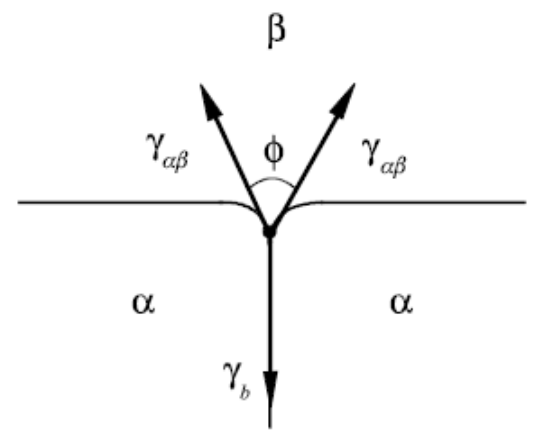

Figure 4.7. Schematic representation of dihedral angle.

In sintering, the parameters affecting the end result can be divided into two parts: process variables and material variables. Process variables include temperature, pressure, heating and cooling rates, and atmosphere. For material variables, powder composition, purity, particle size and distribution can be mentioned. Temperature is probably the most important parameter, as it is the main one that determines diffusion processes. Increasing temperature leads to increased grain boundary diffusion making densification more favourable over coarsening.

Pressure is another important parameter, which is often used to differentiate between various sintering methods. Increased pressure would decrease the pores even before heating and enhance the reaction rate, thus improving densification. In pressureless sintering, however, as the name suggests, no external pressure is applied and material synthesis is performed at atmospheric pressure. Compared to methods where pressure is applied simultaneously with heating, it is cheaper and easier to scale, which makes it more appealing in commercial applications.

Choosing the appropriate gas atmosphere for sintering is essential. Some gases promote coarsening, whereas others densification. The gases that increase the diffusivity promote densification, however those that increase vapour pressure lead to coarsening.

Particle sizes and their distribution of commercially available powders is described using mesh sizes. For example, a "-200 mesh" powder means that at least $90 \%$ of particles will pass through respective 200-mesh sieve, corresponding to $74 \mu \mathrm{m}$ particle size, meaning that powder consists of at least $90 \%$ particles of size $74 \mu \mathrm{m}$ or smaller. There is also a "+" mesh notion, which means that those particles are retained. It is often used in combination of 
“-” mesh label, e.g. “- $100+325$ mesh" powder, which means that at $>90 \%$ of particles will pass through a 325 -mesh sieve ( $44 \mu \mathrm{m}$ particle size) but will be retained by a 100 -mesh sieve ( $149 \mu \mathrm{m}$ particle size), i.e., $>90 \%$ of particles will have sizes in range from 44 to $149 \mu \mathrm{m}$. The particle size distribution in the mixture should ideally be chosen to be in a narrow range, as it will lead to homogenous end products, and a large size distribution or grain size will result in similar non-uniformities, respectively.

$\mathrm{Ga}$ is an element with low melting point $\left(30{ }^{\circ} \mathrm{C}\right)$, and thus it is not generally commercially available as a fine powder. Instead, it is usually sold as rods or pellets. Thus, it is not easily mixed with other powders. Therefore, Ga pellets can be either placed on top of the other constituent powder mixture [9] or mixed together with other powders [118] and upon melting it will mix and react with the powder mixture 


\section{MATERIALS CHARACTERIZATION}

\subsection{X-ray diffraction}

X-ray diffraction (XRD) is a simple yet very powerful non-destructive technique for identification of different crystalline phases in the film, as well as crystal texture, crystal quality, grain size, stress, etc.

X-rays are electromagnetic radiation with wavelength ranging from $0.1 \AA$ to $50 \AA$, which is on the same order as atomic separation distances in crystals. As atoms are arranged in a periodic manner in a crystal, irradiating such sample with X-rays results in constructive interference of the scattered X-rays from the periodic lattice when Bragg's law is fulfilled:

$$
2 d \sin \theta=n \lambda
$$

where $d$ is the spacing between atomic planes, $\theta$ is the scattering angle, $n$ is an integer, and $\lambda$ is the wavelength, see Figure 5.1. 


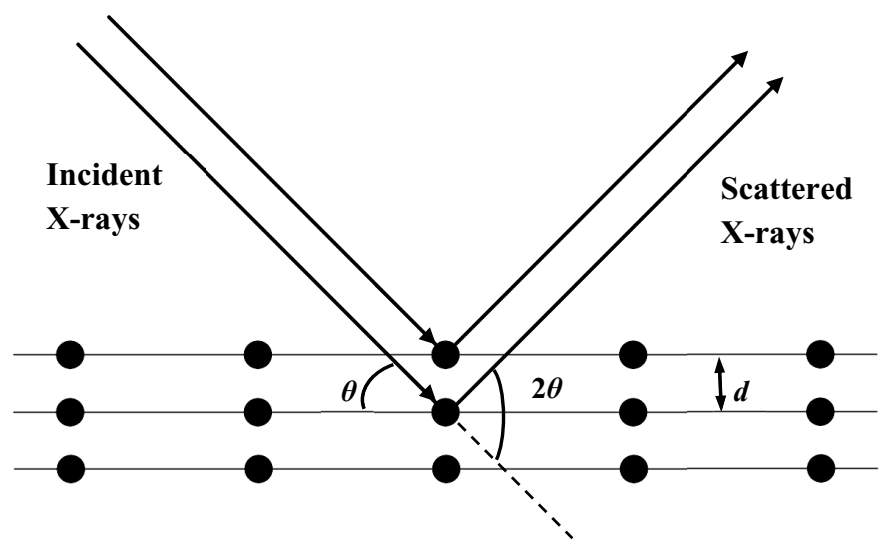

Figure 5.1. Simplified schematic drawing of X-ray diffraction.

Bragg's law is the minimum requirement for diffraction. Condition for constructive interference is also determined by the structure factor of the crystal. The combination of crystal structure and composition is what uniquely defines a material and makes identification of different phases possible. The combination determines the diffractogram of a crystalline material, which is the characteristic set of diffraction angles and diffracted beam intensities.

Widely used are measurements in $\theta-2 \theta$ geometry, where the detection angle is the same as the incidence angle are widely used. Both angles are changed simultaneously, thus it is a symmetric scan. In this geometry (i.e. without tilting the sample), only lattice planes parallel to the surface are probed. For polycrystalline samples, e.g., powder, the planes are oriented randomly and are present in all directions in the sample. Therefore, there will always be planes that are parallel to the surface and all allowed reflections can be detected. In the case of thin films, however, some crystal growth directions may be more favourable than others, resulting in a textured film, meaning that only the peaks from certain set of planes are present. For example, for a MAX phase grown with $c$-axis perpendicular to the substrate, only the so called basal plane $(000 \ell)$ peaks appear in the diffractogram, see Figure 5.2. 


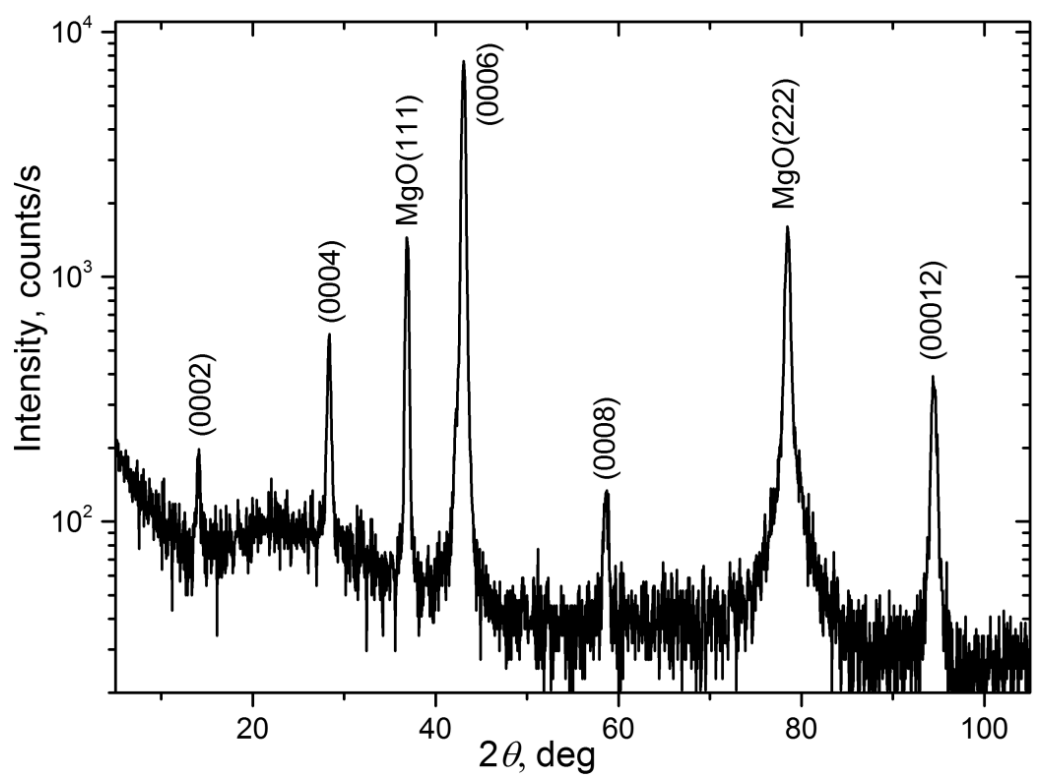

Figure 5.2. XRD $\theta / 2 \theta$ scan of a $\left(\mathrm{Cr}_{0.5} \mathrm{Mn}_{0.5}\right)_{2} \mathrm{GaC}$ thin film deposited on $\mathrm{MgO}(111)$ substrate. Only basal plane peaks from the MAX phase and substrate peaks are visible in the diffractogram.

As established before, in a symmetric $\theta-2 \theta$ geometry, the signal originates only from the atomic planes that are oriented parallel to the sample surface. This only accounts for a fraction of the crystalline planes of the phase. To obtain information about different orientations in the crystal, pole measurements are performed. In pole measurements, the probed $2 \theta$ angle is fixed and selected to match the desired atomic spacing. Then the sample is tilted along the azimuth $\chi$ and rotated along $\varphi$ (Figure 4.3). The data most commonly is presented in circular colour maps displaying intensity in polar coordinates $I(\chi, \varphi)$. Randomly oriented samples will show uniformly distributed intensity at all $\chi$ and $\varphi$ angles. Textured films, where grains are oriented in the same way out-of-plane but randomly in-plane will show diffraction at certain $\chi$ values and for all $\varphi$ values, displayed as circles in pole figure. However, for the films that are epitaxial, i.e. grains are oriented in a way determined by the substrate both out-of-plane and in-plane, diffraction occurs only at certain values of $\chi$ and $\varphi$, which is seen as spots in pole figures. The number of spots and distance between them is determined by the symmetry of the crystal plane that is analysed. The $\chi$ is then the angle between the plane that is analysed and the planes that are parallel to the surface. These measurements help to determine the epitaxial 
relationship between the substrate and the film as well as are a very powerful tool to confirm a crystal structure of an unknown phase in the film.

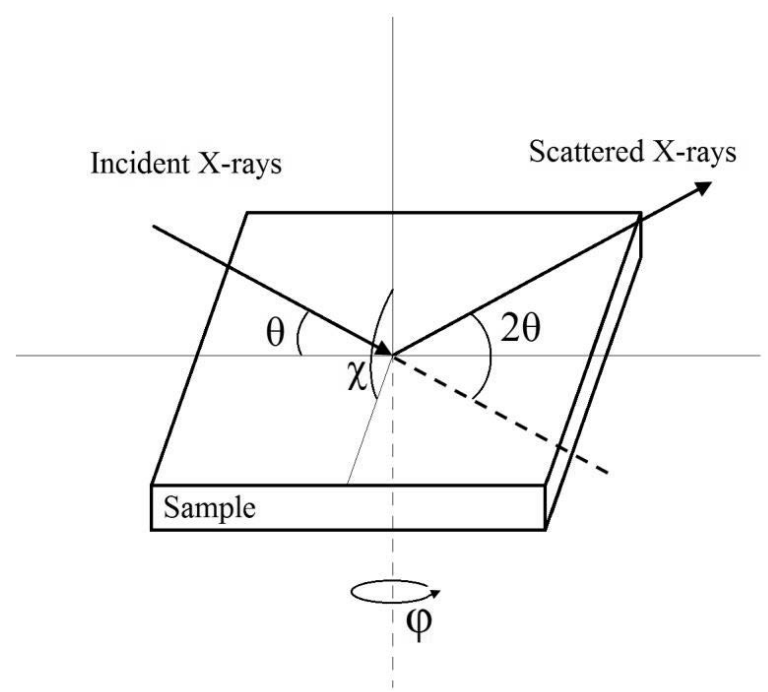

Figure 5.3. Schematic drawing of a pole measurement.

\subsection{X-ray reflectivity}

$\mathrm{X}$-ray reflectivity (XRR) is a method based on the symmetric $\theta-2 \theta$ geometry at grazing angles, where the probed spacing becomes comparable to film thickness, and scattering occurs from film surface and interfaces. It is a useful method providing information such as thickness, density and roughness. XRR analysis can be performed on both crystalline and amorphous materials, however, the surfaces should be smooth and interfaces sharp, and the films should be thin, typically less than $100 \mathrm{~nm}$.

\subsection{Transmission electron microscopy}

Transmission electron microscopy (TEM) is a very useful analysis technique for investigating samples on atomically resolved scale. The essence of TEM is very similar to that of an optical microscope. The resolution of the optical microscope is limited by the wavelength of the incident light $(\sim 500 \mathrm{~nm})$, and therefore, for improved resolution, radiation with shorter wavelength must be used. Concluded from the wave-particle duality, electrons accelerated to $200 \mathrm{keV}$ have a resulting wavelength of $2.5 \mathrm{pm}$. This electron beam is focused with 


\section{CHAPTER 5 - MATERIALS CHARACTERIZATIONS}

electromagnetic lenses, and the point resolution achieved is usually $\sim 1 \AA$, which enables atomically resolved analysis.

Thin film TEM sample preparation is destructive to part of the sample. Ideally, the samples should be to be very thin $(<100 \mathrm{~nm}$, depends on the acceleration voltage used) over a large area, contain no artefacts from the preparation process, be clean from contaminants, be fairly conductive and non-magnetic, as well as able to represent the whole sample.

As the electron beam irradiates the sample, the beam is not only transmitted but also scattered, absorbed and diffracted. Other types of signals are generated after interaction with the sample, such as X-rays, secondary and Auger electrons. This makes interpretation of TEM results non-trivial.

Contrast in TEM can be generated in several ways. Diffraction contrast is formed when a coherent electron beam is scattered elastically after being irradiated on the sample according to Bragg's law. A diffraction pattern is created in the form of spots, where the centre spot corresponds to the incident beam and the other spots correspond to a certain set of atomic planes. Images can be generated from these spots or set of spots by inserting an objective aperture in the diffraction plane. In bright field, only the transmitted beam is allowed to pass through the apertures while other diffracted beams are blocked. In dark field, the transmitted beam is blocked but other diffracted beams are allowed to pass through. This aperture can help to investigate various features in the sample, e.g., dislocations, strain, etc.

For high resolution TEM (HR-TEM) imaging, phase contrast is used. As an electron wave goes through the sample, it interacts with the crystal potential and experiences a phase shift. The phase is also shifted by the microscope, which is conventionally defined by the contrast transfer function (CTF). For conventional (not aberration corrected) electron microscopes, the contrast function can exhibit contrast reversal and oscillations, making it challenging to interpret the contrast in HR-TEM images. An example of a HR-TEM image is shown in Figure 5.4. 


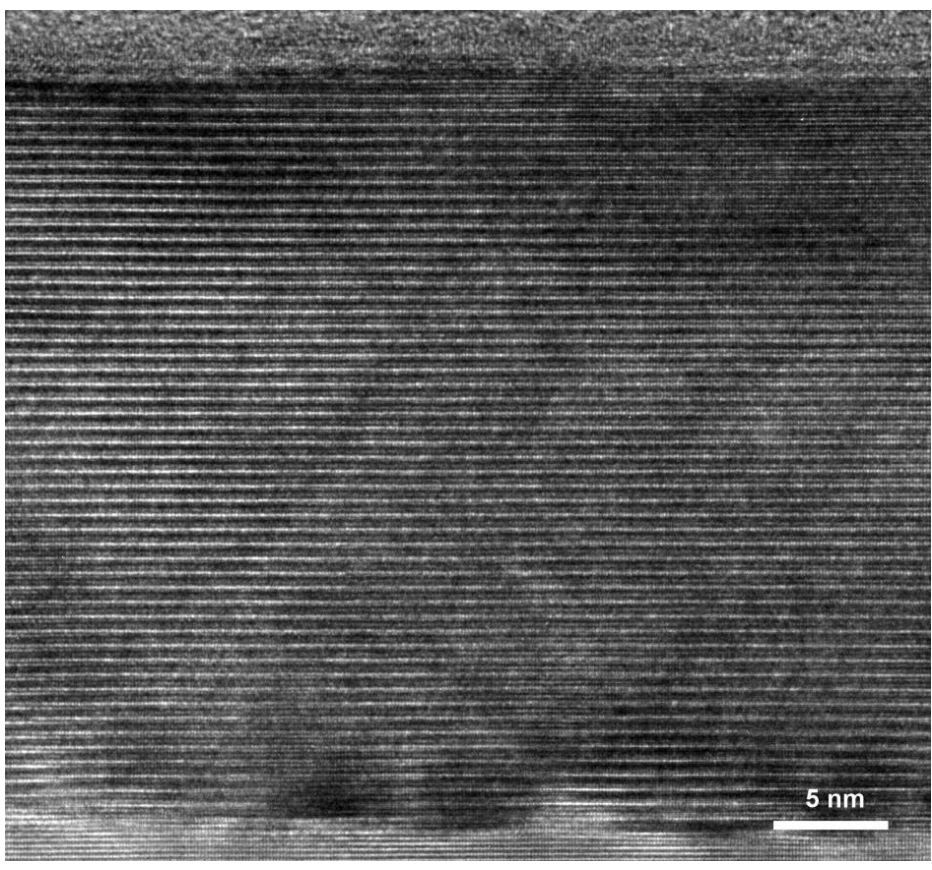

Figure 5.4. HR-TEM image of $\left(\mathrm{Cr}_{0.5} \mathrm{Mn}_{0.5}\right)_{2} \mathrm{GaC}$ MAX phase (middle) and $\mathrm{MgO}$ substrate (bottom)

Scanning transmission electron microscopy (STEM) is an operation mode in TEM where an electron beam is focused into a fine electron probe which is scanning the sample. Each pixel on the resulting image is generated by the scattered intensity at that point. The resolution is thus determined by the size of the electron probe. Typically, these images are recorded by the high-angle annular dark-field (HAADF) detector. In this setup, the detected intensity $(I)$ is proportional to the square of atomic number $(Z)$ and specimen thickness $(t)$ : $I \sim Z^{2} t$. Images formed by this contrast are relatively easy to interpret and allows imaging of sample regions that are too thick to be imaged with conventional TEM.

\subsubsection{Electron diffraction}

A diffraction pattern is formed together with the TEM image, and the setup can therefore be set so that the diffraction plane is projected on the screen or recording device, rather than the image. It provides information about lattice spacing, crystal structure, and orientation. Also, an aperture can be inserted in the image plane, allowing analysis of a diffraction pattern 


\section{CHAPTER 5 - MATERIALS CHARACTERIZATIONS}

obtained from a specific region of the sample. This can be used to gather information from a single grain in a sample containing different phases.

\subsubsection{Energy dispersive X-ray spectroscopy}

When irradiated by an electron beam, the electrons in the sample atoms are excited to higher levels, and when de-excitation to ground level occurs, photons (X-rays) or electrons (Auger electrons) are emitted. Since each atom has a unique atomic structure, there is also a set of unique peaks in X-ray spectrum, allowing elemental identification and bonding information. The method is called energy dispersive X-ray spectroscopy (EDX or EDS)

\subsection{Vibrating sample magnetometry}

Vibrating sample magnetometry (VSM) is a method that measures the magnetic properties of the sample. It was developed in 1955 by Foner [119].

The method is based on Faraday's law, which states that an electromotive force (emf) will be generated in a coil when there is a change in the flux linking the coil. If a constant magnetic field $H_{0}$ is applied to the coil and a sample with magnetization $M$ is placed inside the coil, an output signal will be generated, which is proportional only to the magnetization $M$ and independent of the applied magnetic field $H_{0}$.

Figure 5.5. shows a simple VSM setup. The sample is mounted on a rod that is moved (vibrated) sinusoidally with frequency $f$, and corresponding voltage is induced in pickup coils with the same frequency. The voltage is proportional to the magnetic moment of the sample, vibration amplitude and frequency $f$. To avoid additional errors in determining the magnetic moment due to amplitude and frequency instability, a nulling technique is often employed. A vibrating capacitor is used (not shown in Figure 5.5.), to generate a reference signal, which is varying with amplitude and frequency, and is recorded in the same way as signal from pickup coils. By processing both signals, it is possible to eliminate the errors arising from amplitude and frequency variations, obtaining only the signal from magnetic moment of the sample. 


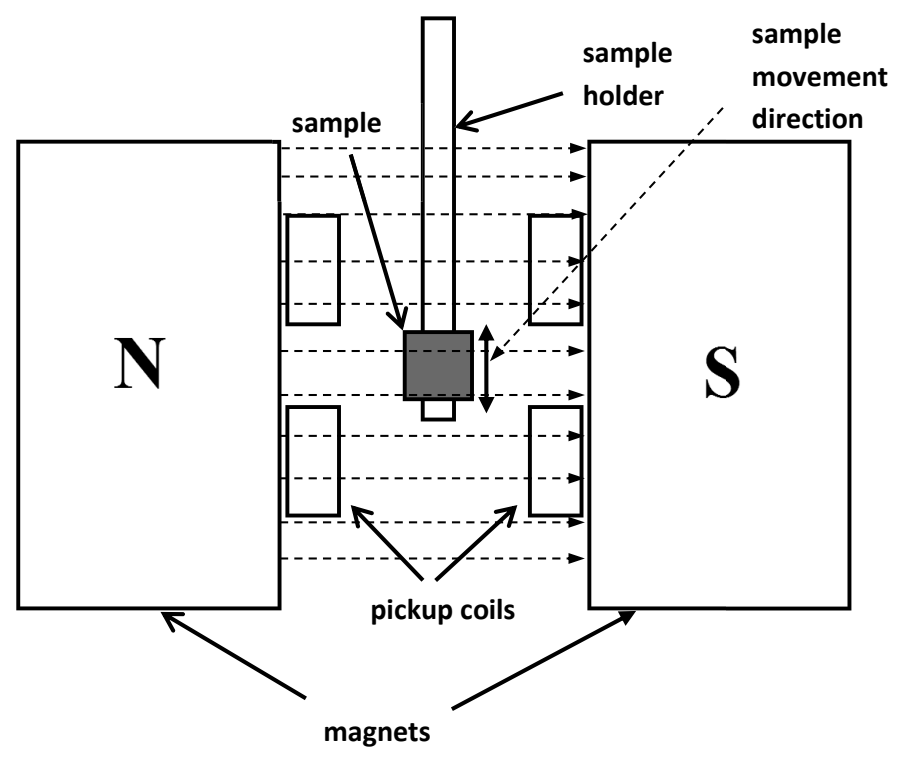

Figure 5.5. Schematic of a VSM measurement setup.

\subsection{SQUID magnetometry}

SQUID [120] stands for Superconducting QUantum Interference Device, which makes use of two physical phenomena - the flux quantization and Josephson junction. These devices are simply put, flux to voltage transducers. The quantization of magnetic flux was first suggested by London [121] in 1950, and later confirmed experimentally by Deaver and Fairbanks [122], and also independently by Doll and Näbauer [123]. It was shown that the flux within a superconductive ring is quantized in units

$$
\Phi_{0}=\frac{h}{2 e} \cong 2.1 \cdot 10^{-15} \mathrm{~T} \cdot m^{2}
$$

where $h$ is Planck constant and $e$ is the electron charge.

In 1962 Josephson predicted that Cooper pairs will tunnel through two superconductors that are separated by an insulating layer [124]. It was a year later that the Josephson tunnelling effect was observed by Anderson and Rowell [125]. These Cooper pairs can be described in the same way as a free particle wavefunction, thus in the absence of electrical voltage, a current proportional to the phase difference can flow in the junction, expressed as 


$$
I=I_{0} \sin (\Delta \varphi)
$$

where $I_{0}$ is the critical current and $\Delta \varphi$ is the phase difference between Cooper pair wavefunctions in two superconductors on each side of the barrier. It was also shown that this description is valid not only for an insulating barrier but all weakly-coupled superconductors, namely using non-superconductive metal barrier or a weak-link (narrowing) in the superconductor itself.

Later, a configuration with two Josephson junctions in parallel was created and both slowly varying modulation as well as rapid oscillations when measuring Josephson current. The periodicity of the small oscillations was equal to a flux quantum, with maxima appearing at fluxes that are integer values of flux quanta. The oscillations were an analogy to the doubleslit experiment. The observation of these oscillations was the beginning of the direct current (DC) SQUID magnetometry.

A few years later, a radio frequency (RF) SQUID was developed, which consisted of a superconductive loop with a single Josephson barrier [126].

Thus the two types of SQUID exist: DC and RF. Due to the flux quantization, they are the most sensitive detectors of magnetic flux, being able to detect a single quanta of flux. They are able to measure static field as well as frequencies up to at least $1 \mathrm{GHz}$. They are able to measure magnetic field, gradient, susceptibility etc. Being so extremely sensitive, SQUID has found numerous applications in various fields, e.g., magnetoencephalography [127], magnetocardiography [128], and biosensing of magnetic markers $[129,130]$ to name a few.

\subsection{Ferromagnetic resonance spectroscopy}

Ferromagnetic resonance (FMR) or formally, resonant absorption of external electromagnetic radiation in ferromagnetic materials [131], is a method that determines magnetic properties by analysing the precessional motion of magnetization vector in a ferromagnetic sample. The resonant Larmour precision in ferromagnets was theoretically predicted in 1935 by Landau and Lifshitz [132], which was later confirmed experimentally in 1946 by Griffiths [133] and independently by Zavoisky [134], however, the resonance absorption was first observed by Arkad'ev V.K. [135] in as early as 1911.

Ferromagnetic resonance is closely related to electron paramagnetic resonance (EPR). In classical description, magnetic moment precesses around the local effective magnetic field 


\section{CHAPTER 5 - MATERIALS CHARACTERIZATIONS}

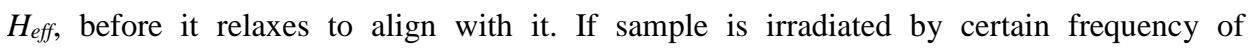
microwaves, usually in 1-100 GHz range, and when this frequency matches the precessional (Larmour) frequency, resonance is achieved and the radiation is absorbed by the material. In 1955, Gilbert modified the original Landau-Lifshitz equations by replacing the damping term resulting in Landau-Lifshitz-Gilbert equation [136]:

$$
\frac{d \vec{M}}{d t}=-\gamma\left[\vec{M} \times\left(\vec{H}_{e f f}\right)\right]+\frac{G}{\gamma M^{2}}\left(\vec{M} \times \frac{\partial \vec{M}}{\partial t}\right)
$$

where $M$ is the magnetic moment and $H_{\text {eff }}$ is the local effective magnetic field, which includes externally applied magnetic field $H$, the demagnetizing field, the magnetocrystalline anisotropy field, and magnetization excitation field. $\gamma=\frac{g \mu_{B}}{\hbar}$ is the gyromagnetic ratio, $g$ is spectroscopic splitting factor, and $G$ is the Gilbert damping constant, characteristic of the material. In this equation, on the right-hand side, the first term describes the precessional motion of magnetic moment around $H_{\text {eff }}$ and the second term describes the damping of the precession. Although there exists several models for the damping term, the Gilbert damping term works best when damping is large, usually the case for thin ferromagnetic films.

In quantum description, this absorption can be explained in terms of Zeeman splitting of energy levels, where in a simple case, illustrated in Figure 5.6, the system has a discreet energy $E$ with no magnetic field applied. In an external magnetic field, this energy level splits into two. In this external magnetic field, the electron can absorb a photon (radiowave) with energy $E=h v=g \mu_{B} H$, where $v$ is the frequency, $g$ is g-factor (spectroscopic splitting factor), $\mu_{\mathrm{B}}$ is the Bohr magneton and $H$ is the magnetic field strength. In practice, the magnetic field is the varied parameter, since due to practical reasons, it is easier to vary over a large range, rather than the frequency. Frequency that is used in experiments is usually denoted as fixed frequency within a certain band in radio frequency spectra (e.g. K-band or Xband). 


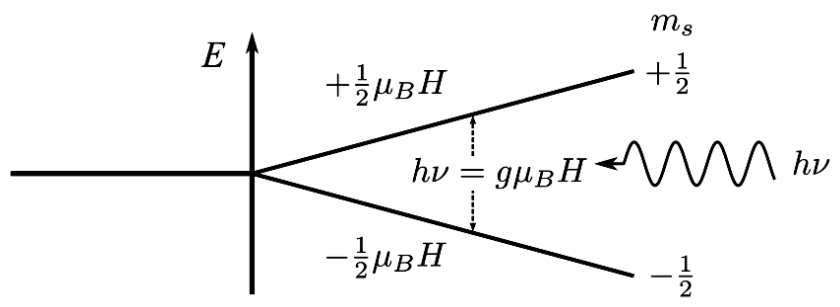

Figure 5.6. Simple schematics for microwave absorption by a free electron in external magnetic field.

Typically, in FMR experiment, the derivative of the absorptive part $\chi$ ” of the complex susceptibility $\chi$ is recorded by changing the applied magnetic field at constant microwave frequency. The typical signal is shown in Figure 5.7. The signal (Figure 5.7. inset) shape is purely Lorentzian and the FWHM is depends on the damping parameter G. The resonance field position $H_{\text {res }}$ depends on magnetization, g-factor, anisotropy, and sample geometry. Additionally, anisotropy parameters of a single crystalline sample can be determined from angle dependent measurements of the sample. Thus, FMR has many applications in studying magnetic nanoscale systems, allowing to quantitatively obtain main magnetic parameters for magnetic anisotropy, interlayer exchange coupling, spectroscopic splitting factor and relaxation in magnetic materials.

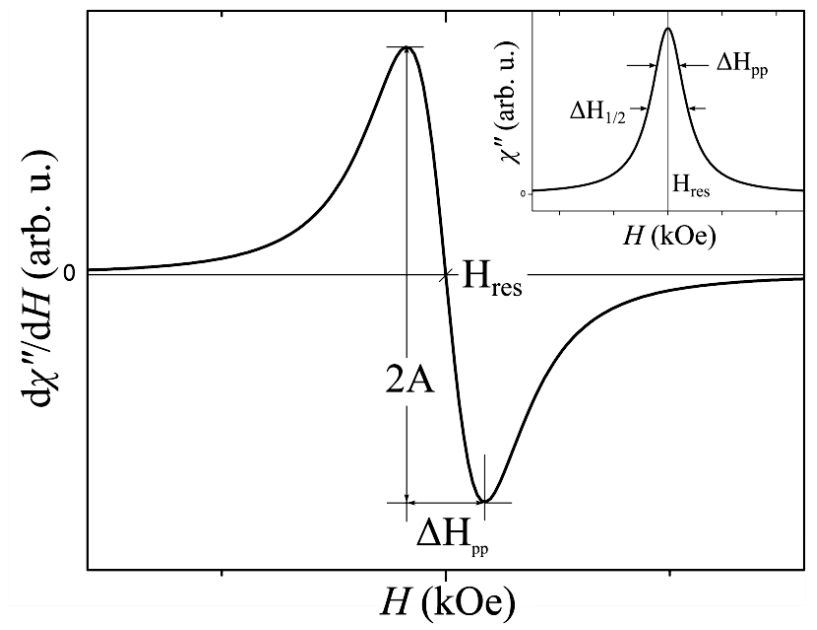

Figure 5.7. Typical measurement spectrum, where the $H$ derivative of $\chi$ " is plotted versus magnetic field. The inset shows absorptive part $\chi$ ” versus magnetic field $H$, which has a pure Lorentzian peak shape. 



\section{6}

\section{SUMMARY AND CONTRIBUTIONS TO THE FIELD}

This Thesis investigates synthesis and properties of materials belonging to a group of inherently nanolaminated carbides called MAX phases, in particular thin film growth and magnetic properties. The focus has been directed towards the materials containing $\mathrm{Ga}$ as $A$-element, and $\mathrm{Cr}$ and/or $\mathrm{Mn}$ as $M$-element. Importantly, through discovery of $\mathrm{Mn}_{2} \mathrm{GaC}, \mathrm{Mn}$ was introduced as a new element to the class of MAX phases, and have allowed introduction of magnetic properties. In this chapter, I will briefly summarize results from my work and well as contributions I brought to the field.

Ga has a low melting point $\left(\mathrm{T}=30^{\circ} \mathrm{C}\right)$, thus during sputtering it will become liquid, even with water cooling. Therefore a concave stainless steel crucible was designed and optimized for a stable plasma production from the $\mathrm{Ga}$ target. For proof-of-concept, a previously known (from bulk synthesis) material, $\mathrm{Cr}_{2} \mathrm{GaC}$, was chosen as a starting point for synthesis. From realized epitaxial thin films of $\mathrm{Cr}_{2} \mathrm{GaC}$, it was demonstrated that elemental Ga can be successfully used in sputtering for synthesis of MAX phases, opening a field of possibilities for synthesis of known or new Ga containing materials in thin film form. It should be stressed that the synthesis procedures developed are not limited to growth of MAX phases.

Thin film deposition is a process involving many empirical parameters, and transfer of these parameters between different deposition systems, for reproducible materials synthesis, can be challenging. I have demonstrated an approach that was developed for facilitating reproduction of films of high crystal quality, and to ensure transfer of optimal synthesis parameters, even between different deposition systems. Again, this method can be applied to MAX phases as well as other phases within higher order materials systems, and serve to minimize trial-and-error procedures, for efficient and controlled materials synthesis. 
Following the thin film synthesis of $\mathrm{Cr}_{2} \mathrm{GaC}$, I also synthesized $\left(\mathrm{Cr}_{0.5} \mathrm{Mn}_{0.5}\right)_{2} \mathrm{GaC}$ thin films, at different temperatures and on different substrates. Films of highest crystal quality were obtained for $\mathrm{MgO}(111)$ substrates at a deposition temperature of $600{ }^{\circ} \mathrm{C}$. Magnetic measurements suggested a complex magnetic behaviour, with moments in the basal plane being ferromagnetically coupled. Hence, the material can be described as a $2 \mathrm{D}$ laminar ferromagnet.

The most exciting part of studying the $\left(\mathrm{Cr}_{1-x} \mathrm{Mn}_{x}\right) 2 \mathrm{GaC}$ system was the synthesis of $\mathrm{Mn}_{2} \mathrm{GaC}$, which was challenging, since material is realized in a very limited temperature range. Also, there exists a competing phase - the inverse perovskite $\mathrm{Mn}_{3} \mathrm{GaC}$, which has a very similar composition, making the optimal parameter space for $\mathrm{Mn}_{2} \mathrm{GaC}$ synthesis very sensitive. $\mathrm{Mn}_{2} \mathrm{GaC}$ has been characterized and its magnetic ground state has been identified as non-collinear (canted) AFM with long range ordering [55].

Altogether, I have shown that the $\left(\mathrm{Cr}_{1-x} \mathrm{Mn}_{x}\right)_{2} \mathrm{GaC}$ system is stable over the whole composition range of $0 \leq \mathrm{x} \leq 1$, and that incorporation of Mn makes this system display a ferromagnetic component in an overall approximate AFM configuration. The synthesis has verified the predictive $a b$ initio calculations, showing that the theoretical approach is credible also for magnetic materials. To date, there are no reports on $\mathrm{Mn}_{2} \mathrm{GaC}$ from bulk synthesis, though further studies on $\mathrm{Mn}_{2} \mathrm{GaC}$ are highly encouraged. With these results, a good model system allowing a stepwise increase in $\mathrm{Mn}$ content has been presented, from pure $\mathrm{Cr}_{2} \mathrm{GaC}$ to pure $\mathrm{Mn}_{2} \mathrm{GaC}$. This is important for tuning the magnetic properties, as well as being a good test-bench for magnetic modelling.

On the new topic of chemically ordered nanolaminates, I have also synthesized two new $i$-MAX phases, including the first ever Mn-containing $i$-MAX phase. This approach have realized a material in bulk form with $\mathrm{Mn}$ as the majority $M$-element, which is a more than two-fold increase in Mn content from previously reported studies. Magnetic characteristics remains to be investigated.

In summary, the knowledge from this Thesis can be directly applied in thin film depositions of a wide range of materials that include $\mathrm{Ga}$ as one of the elements. Furthermore, the optimization procedures presented can be applied to thin film synthesis in general, leading to more efficient materials synthesis and an improved thin film quality. Finally, the novel materials reported herein, especially those including new elements within the MAX-phase family, will fuel further studies and increase the interest in the field in general. 


\section{7}

\section{BIBLIOGRAPHY}

[1] J.B. Carlson, "Lodestone Compass: Chinese or Olmec Primacy?: Multidisciplinary analysis of an Olmec hematite artifact from San Lorenzo, Veracruz, Mexico". Science 189 (1975) 753-760.

[2] P. Eklund, M. Beckers, U. Jansson, H. Högberg, and L. Hultman, "The $\mathrm{M}_{n+1} \mathrm{AX}_{n}$ phases: Materials science and thin-film processing". Thin Solid Films 518 (2010) 1851-1878.

[3] M.W. Barsoum, "The $\mathrm{M}_{\mathrm{N}+1} \mathrm{AX}_{\mathrm{N}}$ phases: A new class of solids: Thermodynamically stable nanolaminates". Progress in Solid State Chemistry 28 (2000) 201-281.

[4] W. Jeitschko, H. Nowotny, and F. Benesovsky, "Kohlenstoffhaltige ternäre Verbindungen (V-Ge-C, Nb-Ga-C, Ta-Ga-C, Ta-Ge-C, Cr-Ga-C und Cr-Ge-C)". Monatshefte für Chemie / Chemical Monthly 94 (1963) 844-850.

[5] J. Rosen, M. Dahlqvist, S.I. Simak, D.R. McKenzie, and M.M.M. Bilek, "Oxygen incorporation in $\mathrm{Ti}_{2} \mathrm{AlC}$ : Tuning of anisotropic conductivity". Applied Physics Letters 97 (2010) 073103.

[6] M.W. Barsoum, MAX Phases: Properties of Machinable Ternary Carbides and Nitrides. (2013).

[7] M. Magnuson, and M. Mattesini, "Chemical bonding and electronic-structure in MAX phases as viewed by X-ray spectroscopy and density functional theory". Thin Solid Films 621 (2017) 108-130.

[8] A.S. Ingason, M. Dahlqvist, and J. Rosen, "Magnetic MAX phases from theory and experiments; a review". Journal of Physics: Condensed Matter 28 (2016) 433003.

[9] A. Mockute, J. Lu, E.J. Moon, M. Yan, B. Anasori, S.J. May, M.W. Barsoum, and J. Rosen, "Solid Solubility and Magnetism upon Mn Incorporation in the Bulk Ternary Carbides $\mathrm{Cr}_{2} \mathrm{AlC}$ and $\mathrm{Cr}_{2} \mathrm{GaC}$. Materials Research Letters 3 (2014) 16-22. 
[10] M. Dahlqvist, J. Lu, R. Meshkian, Q. Tao, L. Hultman, and J. Rosen, "Prediction and synthesis of a family of atomic laminate phases with Kagomé-like and in-plane chemical ordering". Science Advances 3 (2017) e1700642.

[11] Q. Tao, M. Dahlqvist, J. Lu, S. Kota, R. Meshkian, J. Halim, J. Palisaitis, L. Hultman, M.W. Barsoum, P.O.Å. Persson, and J. Rosen, "Two-dimensional Mo1.33C MXene with divacancy ordering prepared from parent 3D laminate with in-plane chemical ordering". 8 (2017) 14949.

[12] V.H. Nowotny, "Strukturchemie einiger Verbindungen der Übergangsmetalle mit den elementen C, Si, Ge, Sn". Progress in Solid State Chemistry 5 (1971) 27-70.

[13] M.W. Barsoum, and T. El-Raghy, "Synthesis and Characterization of a Remarkable Ceramic: $\mathrm{Ti}_{3} \mathrm{SiC}_{2}$ ". Journal of the American Ceramic Society 79 (1996) 1953-1956.

[14] J. Emmerlich, H. Hogberg, S. Sasvari, P.O.A. Persson, L. Hultman, J.-P. Palmquist, U. Jansson, J.M. Molina-Aldareguia, and Z. Czigany, "Growth of $\mathrm{Ti}_{3} \mathrm{SiC}_{2}$ thin films by elemental target magnetron sputtering". Journal of Applied Physics 96 (2004) 48174826.

[15] J.P. Palmquist, S. Li, P.O.Å. Persson, J. Emmerlich, O. Wilhelmsson, H. Högberg, M.I. Katsnelson, B. Johansson, R. Ahuja, O. Eriksson, L. Hultman, and U. Jansson, $" M_{n+1} A X_{n}$ phases in the Ti-Si-C system studied by thin-film synthesis and ab initio calculations". Physical Review B 70 (2004) 165401.

[16] H. Högberg, P. Eklund, J. Emmerlich, J. Birch, and L. Hultman, "Epitaxial Ti2 GeC, $\mathrm{Ti}_{3} \mathrm{GeC}_{2}$, and $\mathrm{Ti}_{4} \mathrm{GeC}_{3} \mathrm{MAX}$-phase thin films grown by magnetron sputtering". Journal of Materials Research 20 (2005) 779-782.

[17] S. Kuchida, T. Muranaka, K. Kawashima, K. Inoue, M. Yoshikawa, and J. Akimitsu, "Superconductivity in $\mathrm{Lu}_{2} \mathrm{SnC}$ ". Physica C: Superconductivity 494 (2013) 77-79.

[18] M. Naguib, M. Kurtoglu, V. Presser, J. Lu, J. Niu, M. Heon, L. Hultman, Y. Gogotsi, and M.W. Barsoum, "Two-Dimensional Nanocrystals Produced by Exfoliation of $\mathrm{Ti}_{3} \mathrm{AlC}_{2}$ ". Advanced Materials 23 (2011) 4248-4253.

[19] M.W. Barsoum, and M. Radovic, "Elastic and Mechanical Properties of the MAX Phases". Annual Review of Materials Research 41 (2011) 195-227.

[20] J. Emmerlich, P. Eklund, D. Rittrich, H. Högberg, and L. Hultman, "Electrical resistivity of $\mathrm{Ti}_{n+1} \mathrm{AC}_{n}(\mathrm{~A}=\mathrm{Si}, \mathrm{Ge}, \mathrm{Sn}, n=1-3)$ thin films". Journal of Materials Research 22 (2007) 2279-2287. 
[21] J. Emmerlich, G. Gassner, P. Eklund, H. Högberg, and L. Hultman, "Micro and macroscale tribological behavior of epitaxial $\mathrm{Ti}_{3} \mathrm{SiC}_{2}$ thin films". Wear 264 (2008) 914-919.

[22] A. Mendoza-Galván, M. Rybka, K. Järrendahl, H. Arwin, M. Magnuson, L. Hultman, and M.W. Barsoum, "Spectroscopic ellipsometry study on the dielectric function of bulk $\mathrm{Ti}_{2} \mathrm{AlN}, \mathrm{Ti}_{2} \mathrm{AlC}, \mathrm{Nb}_{2} \mathrm{AlC}$, $\left(\mathrm{Ti}_{0.5}, \mathrm{Nb}_{0.5}\right)_{2} \mathrm{AlC}$, and $\mathrm{Ti}_{3} \mathrm{GeC}_{2} \mathrm{MAX}$-phases". Journal of Applied Physics 109 (2011) 013530.

[23] A.S. Ingason, A. Mockute, M. Dahlqvist, F. Magnus, S. Olafsson, U.B. Arnalds, B. Alling, I.A. Abrikosov, B. Hjörvarsson, P.O.Å. Persson, and J. Rosen, "Magnetic Self-Organized Atomic Laminate from First Principles and Thin Film Synthesis". Physical Review Letters 110 (2013) 195502.

[24] A. Mockute, M. Dahlqvist, J. Emmerlich, L. Hultman, J.M. Schneider, P.O.Å. Persson, and J. Rosen, "Synthesis and ab initio calculations of nanolaminated $(\mathrm{Cr}, \mathrm{Mn})_{2} \mathrm{AlC}$ compounds". Physical Review B 87 (2013) 094113.

[25] A. Mockute, P.O.Å. Persson, F. Magnus, A.S. Ingason, S. Olafsson, L. Hultman, and J. Rosen, "Synthesis and characterization of arc deposited magnetic ( $\mathrm{Cr}, \mathrm{Mn})_{2} \mathrm{AlC}$ MAX phase films". physica status solidi (RRL) - Rapid Research Letters 8 (2014) 420-423.

[26] C.C. Lai, R. Meshkian, M. Dahlqvist, J. Lu, L.Å. Näslund, O. Rivin, E.N. Caspi, O. Ozeri, L. Hultman, P. Eklund, M.W. Barsoum, and J. Rosen, "Structural and chemical determination of the new nanolaminated carbide $\mathrm{Mo}_{2} \mathrm{Ga}_{2} \mathrm{C}$ from first principles and materials analysis". Acta Materialia 99 (2015) 157-164.

[27] C. Hu, C.C. Lai, Q. Tao, J. Lu, J. Halim, L. Sun, J. Zhang, J. Yang, B. Anasori, J. Wang, Y. Sakka, L. Hultman, P. Eklund, J. Rosen, and M.W. Barsoum, "Mo $\mathrm{Ga}_{2} \mathrm{C}$ : a new ternary nanolaminated carbide". Chemical Communications 51 (2015) 6560-6563.

[28] L. Zheng, J. Wang, X. Lu, F. Li, J. Wang, and Y. Zhou, "( $\left.\mathrm{Ti}_{0.5} \mathrm{Nb}_{0.5}\right)_{5} \mathrm{AlC}_{4}$ : A NewLayered Compound Belonging to MAX Phases". Journal of the American Ceramic Society 93 (2010) 3068-3071.

[29] Z. Lin, M. Zhuo, Y. Zhou, M. Li, and J. Wang, "Microstructures and Theoretical Bulk Modulus of Layered Ternary Tantalum Aluminum Carbides". Journal of the American Ceramic Society 89 (2006) 3765-3769.

[30] J. Zhang, B. Liu, J.Y. Wang, and Y.C. Zhou, "Low-temperature instability of Ti 2 SnC: A combined transmission electron microscopy, differential scanning calorimetry, and x-ray diffraction investigations". Journal of Materials Research 24 (2009) 39-49. 


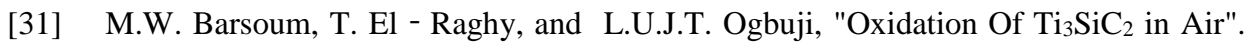
Journal of The Electrochemical Society 144 (1997) 2508-2516.

[32] D.J. Tallman, B. Anasori, and M.W. Barsoum, "A Critical Review of the Oxidation of $\mathrm{Ti}_{2} \mathrm{AlC}, \mathrm{Ti}_{3} \mathrm{AlC}_{2}$ and $\mathrm{Cr}_{2} \mathrm{AlC}$ in Air". Materials Research Letters 1 (2013) 115-125.

[33] W.G. Sloof, R. Pei, S.A. McDonald, J.L. Fife, L. Shen, L. Boatemaa, A.-S. Farle, K. Yan, X. Zhang, S. van der Zwaag, P.D. Lee, and P.J. Withers, "Repeated crack healing in MAX-phase ceramics revealed by 4D in situ synchrotron X-ray tomographic microscopy". Scientific Reports 6 (2016) 23040.

[34] A. Farle, L. Boatemaa, L. Shen, S. Gövert, J.B.W. Kok, M. Bosch, S. Yoshioka, S.v.d. Zwaag, and W.G. Sloof, "Demonstrating the self-healing behaviour of some selected ceramics under combustion chamber conditions". Smart Materials and Structures 25 (2016) 084019.

[35] E.N. Hoffman, D.W. Vinson, R.L. Sindelar, D.J. Tallman, G. Kohse, and M.W. Barsoum, "MAX phase carbides and nitrides: Properties for future nuclear power plant in-core applications and neutron transmutation analysis". Nuclear Engineering and Design 244 (2012) 17-24.

[36] X. Zhang, Z. Zhang, and Z. Zhou, "MXene-based materials for electrochemical energy storage". Journal of Energy Chemistry 27 (2018) 73-85.

[37] F. Shahzad, M. Alhabeb, C.B. Hatter, B. Anasori, S. Man Hong, C.M. Koo, and Y. Gogotsi, "Electromagnetic interference shielding with 2D transition metal carbides (MXenes)". Science 353 (2016) 1137-1140.

[38] M. Naguib, G.W. Bentzel, J. Shah, J. Halim, E.N. Caspi, J. Lu, L. Hultman, and M.W. Barsoum, "New Solid Solution MAX Phases: $\left(\mathrm{Ti}_{0.5}, \mathrm{~V}_{0.5}\right)_{3} \mathrm{AlC}_{2},\left(\mathrm{Nb}_{0.5}, \mathrm{~V}_{0.5}\right)_{2} \mathrm{AlC}$, $\left(\mathrm{Nb}_{0.5}, \mathrm{~V}_{0.5}\right)_{4} \mathrm{AlC}_{3}$ and $\left(\mathrm{Nb}_{0.8}, \mathrm{Zr}_{0.2}\right)_{2} \mathrm{AlC}$. Materials Research Letters2014) 1-8.

[39] T. Cabioch, P. Eklund, V. Mauchamp, M. Jaouen, and M.W. Barsoum, "Tailoring of the thermal expansion of $\mathrm{Cr}_{2}\left(\mathrm{Al}_{x}, \mathrm{Ge}_{1-x}\right) \mathrm{C}$ phases". Journal of the European Ceramic Society 33 (2013) 897-904.

[40] M.W. Barsoum, T. El-Raghy, and M. Ali, "Processing and characterization of $\mathrm{Ti}_{2} \mathrm{AlC}$, $\mathrm{Ti}_{2} \mathrm{AlN}$, and $\mathrm{Ti}_{2} \mathrm{AlC}_{0.5} \mathrm{~N}_{0.5}$ ". Metallurgical and Materials Transactions A 31 (2000) 1857-1865.

[41] J. Rosen, P.O.Å. Persson, M. Ionescu, A. Kondyurin, D.R. McKenzie, and M.M.M. Bilek, "Oxygen incorporation in $\mathrm{Ti}_{2} \mathrm{AlC}$ thin films". Applied Physics Letters 92 (2008) 064102. 
[42] A. Mockute, M. Dahlqvist, L. Hultman, P.O.Å. Persson, and J. Rosen, "Oxygen incorporation in $\mathrm{Ti}_{2} \mathrm{AlC}$ thin films studied by electron energy loss spectroscopy and ab initio calculations". Journal of Materials Science 48 (2013) 3686-3691.

[43] M. Dahlqvist, B. Alling, I.A. Abrikosov, and J. Rosén, "Phase stability of Ti2 AlC upon oxygen incorporation: A first-principles investigation". Physical Review B 81 (2010) 024111.

[44] M. Baben, L. Shang, J. Emmerlich, and J.M. Schneider, "Oxygen incorporation in $\mathrm{M}_{2} \mathrm{AlC}(\mathrm{M}=\mathrm{Ti}, \mathrm{V}, \mathrm{Cr}) "$. Acta Materialia 60 (2012) 4810-4818.

[45] S. Kerdsongpanya, K. Buchholt, O. Tengstrand, J. Lu, J. Jensen, L. Hultman, and P. Eklund, "Phase-stabilization and substrate effects on nucleation and growth of $(\mathrm{Ti}, \mathrm{V})_{n+1} \mathrm{GeC}_{n}$ thin films". Journal of Applied Physics 110 (2011) 053516.

[46] M. Dahlqvist, B. Alling, and J. Rosén, "Stability trends of MAX phases from first principles". Physical Review B 81 (2010) 220102.

[47] P. Eklund, M. Dahlqvist, O. Tengstrand, L. Hultman, J. Lu, N. Nedfors, U. Jansson, and J. Rosén, "Discovery of the Ternary Nanolaminated Compound $\mathrm{Nb}_{2} \mathrm{GeC}$ by a Systematic Theoretical-Experimental Approach". Physical Review Letters 109 (2012) 035502.

[48] W. Luo, and R. Ahuja, "Magnetic $\mathrm{Fe}_{n+1} \mathrm{AC}_{n}(n=1,2,3$, and $\mathrm{A}=\mathrm{Al}, \mathrm{Si}, \mathrm{Ge})$ phases: from ab initio theory". Journal of Physics: Condensed Matter 20 (2008) 064217.

[49] M. Dahlqvist, B. Alling, I.A. Abrikosov, and J. Rosen, "Magnetic nanoscale laminates with tunable exchange coupling from first principles". Physical Review B $\mathbf{8 4}$ (2011) 220403.

[50] M. Bode, M. Heide, K. von Bergmann, P. Ferriani, S. Heinze, G. Bihlmayer, A. Kubetzka, O. Pietzsch, S. Blugel, and R. Wiesendanger, "Chiral magnetic order at surfaces driven by inversion asymmetry". Nature 447 (2007) 190-193.

[51] Q.Z. Tao, C.F. Hu, S. Lin, H.B. Zhang, F.Z. Li, D. Qu, M.L. Wu, Y.P. Sun, Y. Sakka, and M.W. Barsoum, "Coexistence of Ferromagnetic and a Re-entrant Cluster Glass State in the Layered Quaternary $\left(\mathrm{Cr}_{1-\mathrm{x}}, \mathrm{Mn}_{\mathrm{x}}\right)_{2} \mathrm{GeC}$ ". Materials Research Letters 2 (2014) $1-7$.

[52] S. Lin, P. Tong, B.S. Wang, Y.N. Huang, W.J. Lu, D.F. Shao, B.C. Zhao, W.H. Song, and Y.P. Sun, "Magnetic and electrical/thermal transport properties of Mn-doped $M_{n+1} A X_{n}$ phase compounds $\mathrm{Cr}_{2-x} \mathrm{Mn}_{x} \mathrm{GaC}(0 \leqslant x \leqslant 1) "$. Journal of Applied Physics 113 (2013) 053502. 
[53] R. Meshkian, A.S. Ingason, U.B. Arnalds, F. Magnus, J. Lu, and J. Rosen, "A magnetic atomic laminate from thin film synthesis: $\left(\mathrm{Mo}_{0.5} \mathrm{Mn}_{0.5}\right)_{2} \mathrm{GaC}$ ". APL Materials 3 (2015) 076102.

[54] Q. Tao, R. Salikhov, A. Mockute, J. Lu, M. Farle, U. Wiedwald, and J. Rosen, "Thin film synthesis and characterization of a chemically ordered magnetic nanolaminate (V,Mn) ${ }_{3} \mathrm{GaC}_{2} "$. APL Materials 4 (2016) 086109.

[55] A.S. Ingason, G.K. Pálsson, M. Dahlqvist, and J. Rosen, "Long-range antiferromagnetic order in epitaxial $\mathrm{Mn}_{2} \mathrm{GaC}$ thin films from neutron reflectometry". Physical Review B 94 (2016) 024416.

[56] M. Dahlqvist, A.S. Ingason, B. Alling, F. Magnus, A. Thore, A. Petruhins, A. Mockute, U.B. Arnalds, M. Sahlberg, B. Hjörvarsson, I.A. Abrikosov, and J. Rosen, "Magnetically driven anisotropic structural changes in the atomic laminate $\mathrm{Mn}_{2} \mathrm{GaC}$. Physical Review B 93 (2016) 014410.

[57] M. Jaouen, P. Chartier, T. Cabioc'h, V. Mauchamp, G. André, and M. Viret, "Invar Like Behavior of the $\mathrm{Cr}_{2} \mathrm{AlC}$ MAX Phase at Low Temperature". Journal of the American Ceramic Society 96 (2013) 3872-3876.

[58] M. Jaouen, M. Bugnet, N. Jaouen, P. Ohresser, V. Mauchamp, T. Cabioc'h, and A. Rogalev, "Experimental evidence of $\mathrm{Cr}$ magnetic moments at low temperature in $\mathrm{Cr}_{2} \mathrm{~A}(\mathrm{~A}=\mathrm{Al}, \mathrm{Ge}) \mathrm{C} "$. Journal of Physics: Condensed Matter 26 (2014) 176002.

[59] M. Dahlqvist, B. Alling, and J. Rosen, "Correlation between magnetic state and bulk modulus of $\mathrm{Cr}_{2} \mathrm{AlC}$ ". Journal of Applied Physics 113 (2013) 216103-216103.

[60] M. Ramzan, S. Lebègue, and R. Ahuja, "Electronic and mechanical properties of $\mathrm{Cr}_{2} \mathrm{GeC}$ with hybrid functional and correlation effects". Solid State Communications 152 (2012) 1147-1149.

[61] M. Maurizio, and M. Martin, "Electronic correlation effects in the $\mathrm{Cr}_{2} \mathrm{GeC} \mathrm{M}_{n+1} \mathrm{AX}_{n}$ phase". Journal of Physics: Condensed Matter 25 (2013) 035601.

[62] M. Benouis, Y. Azzaz, M. Ameri, O. Arbouche, A. Bennadji, D. Bensaid, and Y. AlDouri, "Electronic and Magnetic Properties of $\mathrm{Cr}_{2} \mathrm{GeC}$ with GGA+U Approximation". Journal of Superconductivity and Novel Magnetism 29 (2016) 1267-1272.

[63] Z. Liu, T. Waki, Y. Tabata, K. Yuge, H. Nakamura, and I. Watanabe, "Magnetic ground state of the $M_{n+1} A X_{n}$-phase nitride $\mathrm{Cr}_{2} \mathrm{GaN} "$. Physical Review B 88 (2013) 134401.

[64] S. Lin, Y. Huang, L. Zu, X. Kan, J. Lin, W. Song, P. Tong, X. Zhu, and Y. Sun, "Alloying effects on structural, magnetic, and electrical/thermal transport properties in 
MAX-phase $\mathrm{Cr}_{2-x} M_{x} \mathrm{GeC}(M=\mathrm{Ti}, \mathrm{V}, \mathrm{Mn}, \mathrm{Fe}$, and Mo)". Journal of Alloys and Compounds 680 (2016) 452-461.

[65] C.M. Hamm, J.D. Bocarsly, G. Seward, U.I. Kramm, and C.S. Birkel, "Nonconventional synthesis and magnetic properties of MAX phases $(\mathrm{Cr} / \mathrm{Mn})_{2} \mathrm{AlC}$ and $(\mathrm{Cr} / \mathrm{Fe})_{2} \mathrm{AlC}$. Journal of Materials Chemistry C 5 (2017) 5700-5708.

[66] C.-C. Lai, A. Petruhins, J. Lu, M. Farle, L. Hultman, P. Eklund, and J. Rosen, "Thermally induced substitutional reaction of $\mathrm{Fe}$ into $\mathrm{Mo}_{2} \mathrm{GaC}$ thin films". Materials Research Letters2017).

[67] Z. Liu, L. Zheng, L. Sun, Y. Qian, J. Wang, and M. Li, "( $\left(\mathrm{Cr}_{2 / 3} \mathrm{Ti}_{1 / 3}\right)_{3} \mathrm{AlC}_{2}$ and $\left(\mathrm{Cr}_{5 / 8} \mathrm{Ti}_{3 / 8}\right)_{4} \mathrm{AlC}_{3}$ : New MAX-phase Compounds in $\mathrm{Ti}-\mathrm{Cr}-\mathrm{Al}-\mathrm{C}$ System". Journal of the American Ceramic Society 97 (2014) 67-69.

[68] Z. Liu, E. Wu, J. Wang, Y. Qian, H. Xiang, X. Li, Q. Jin, G. Sun, X. Chen, J. Wang, and M. Li, "Crystal structure and formation mechanism of $\left(\mathrm{Cr}_{2 / 3} \mathrm{Ti}_{1 / 3}\right)_{3} \mathrm{AlC}_{2} \mathrm{MAX}$ phase". Acta Materialia 73 (2014) 186-193.

[69] B. Anasori, J. Halim, J. Lu, C.A. Voigt, L. Hultman, and M.W. Barsoum, "Mo2 $\mathrm{TiAlC}_{2}$ : A new ordered layered ternary carbide". Scripta Materialia 101 (2015) 5-7.

[70] B. Anasori, M. Dahlqvist, J. Halim, E.J. Moon, J. Lu, B.C. Hosler, E.a.N. Caspi, S.J. May, L. Hultman, P. Eklund, J. Rosén, and M.W. Barsoum, "Experimental and theoretical characterization of ordered MAX phases $\mathrm{Mo}_{2} \mathrm{TiAlC}_{2}$ and $\mathrm{Mo}_{2} \mathrm{Ti}_{2} \mathrm{AlC}_{3} "$. Journal of Applied Physics 118 (2015) 094304.

[71] E.a.N. Caspi, P. Chartier, F. Porcher, F. Damay, and T. Cabioc'h, "Ordering of (Cr,V) Layers in Nanolamellar $\left(\mathrm{Cr}_{0.5} \mathrm{~V}_{0.5}\right)_{n+1} \mathrm{AlC}_{\mathrm{n}}$ Compounds". Materials Research Letters 3 (2015) 100-106.

[72] R. Meshkian, Q. Tao, M. Dahlqvist, J. Lu, L. Hultman, and J. Rosen, "Theoretical stability and materials synthesis of a chemically ordered MAX phase, $\mathrm{Mo}_{2} \mathrm{ScAlC}_{2}$, and its two-dimensional derivate $\mathrm{Mo}_{2} \mathrm{ScC}_{2}$ MXene". Acta Materialia 125 (2017) 476-480.

[73] M. Dahlqvist, J. Lu, R. Meshkian, Q. Tao, L. Hultman, and J. Rosen, "Prediction and synthesis of a family of atomic laminate phases with Kagomé-like and in-plane chemical ordering". Science Advances 3 (2017).

[74] M.A. Ghebouli, B. Ghebouli, A. Bouhemadou, and M. Fatmi, "Theoretical study of the structural, elastic, electronic and thermal properties of the MAX phase $\mathrm{Nb}_{2} \mathrm{SiC}^{\prime}$. Solid State Communications 151 (2011) 382-387. 
[75] A. Grechnev, S. Li, R. Ahuja, O. Eriksson, U. Jansson, and O. Wilhelmsson, "Layered compound $\mathrm{Nb}_{3} \mathrm{SiC}_{2}$ predicted from first-principles theory". Applied Physics Letters 85 (2004) 3071-3073.

[76] L. Chenliang, K. Jeilai, W. Biao, L. Yuanshi, and W. Rui, "A new layer compound $\mathrm{Nb}_{4} \mathrm{SiC}_{3}$ predicted from first-principles theory". Journal of Physics D: Applied Physics 42 (2009) 075404.

[77] C. Li, Z. Wang, D. Ma, C. Wang, and B. Wang, "First-principles study of the structural, mechanical, magnetic, and electronic properties of $\mathrm{Cr}_{4} \mathrm{AlN}_{3}$ under pressure". Intermetallics 43 (2013) 71-78.

[78] E. Fermi, "Un metodo statistico per la determinazione di alcune priorieta dell'atome". Rendicondi Accademia Nazionale de Lincei 32 (1927) 602-607.

[79] L.H. Thomas, presented at the Mathematical Proceedings of the Cambridge Philosophical Society, 1927 (unpublished).

[80] P. Hohenberg, and W. Kohn, "Inhomogeneous Electron Gas". Physical Review 136 (1964) B864-B871.

[81] W. Kohn, and L.J. Sham, "Self-Consistent Equations Including Exchange and Correlation Effects". Physical Review 140 (1965) A1133-A1138.

[82] E.L.P.y. Blancá, C.O. Rodríguez, J. Shitu, and D.L. Novikov, "Degree of localization of the exchange-correlation hole and its influence on the ground-state (structural and magnetic) properties of d metals". Journal of Physics: Condensed Matter 13 (2001) 9463.

[83] A.D. Becke, "Density-functional exchange-energy approximation with correct asymptotic behavior". Physical Review A 38 (1988) 3098-3100.

[84] J.P. Perdew, and Y. Wang, "Accurate and simple analytic representation of the electron-gas correlation energy". Physical Review B 45 (1992) 13244-13249.

[85] J.P. Perdew, K. Burke, and M. Ernzerhof, "Generalized Gradient Approximation Made Simple". Physical Review Letters 77 (1996) 3865-3868.

[86] D. Vanderbilt, "Soft self-consistent pseudopotentials in a generalized eigenvalue formalism". Physical Review B 41 (1990) 7892-7895.

[87] G. Kresse, and D. Joubert, "From ultrasoft pseudopotentials to the projector augmented-wave method". Physical Review B 59 (1999) 1758-1775.

[88] G. Kresse, and J. Hafner, "Ab initio molecular-dynamics simulation of the liquidmetal-amorphous-semiconductor transition in germanium". Physical Review B 49 (1994) 14251-14269. 
[89] G. Kresse, and J. Furthmüller, "Efficiency of ab-initio total energy calculations for metals and semiconductors using a plane-wave basis set". Computational Materials Science 6 (1996) 15-50.

[90] G. Kresse, and J. Furthmüller, "Efficient iterative schemes for $a b$ initio total-energy calculations using a plane-wave basis set". Physical Review B 54 (1996) 11169-11186.

[91] C.M. Fang, R. Ahuja, and O. Eriksson, "Prediction of $M A X$ phases, $\mathrm{V}_{N+1} \operatorname{SiC}_{N}(N=1,2)$, from first-principles theory". Journal of Applied Physics 101 (2007) 013511.

[92] V.J. Keast, S. Harris, and D.K. Smith, "Prediction of the stability of the $M_{n+1} A X n$ phases from first principles". Physical Review B 80 (2009) 214113.

[93] K. Sato, M. Mishra, H. Hirano, C. Hu, and Y. Sakka, "Pressureless Sintering and Reaction Mechanisms of $\mathrm{Ti}_{3} \mathrm{SiC}_{2}$ Ceramics". Journal of the American Ceramic Society 97 (2014) 1407-1412.

[94] J. Zhu, B. Mei, J. Liu, and X. Xu, "Synthesis of high-purity $\mathrm{Ti}_{3} \mathrm{SiC}_{2}$ and $\mathrm{Ti}_{3} \mathrm{AlC}_{2}$ by hot-pressing (HP)". Journal of Materials Science Letters 22 (2003) 1111-1112.

[95] N.V. Tzenov, and M.W. Barsoum, "Synthesis and Characterization of $\mathrm{Ti}_{3} \mathrm{AlC}_{2}$ ". Journal of the American Ceramic Society 83 (2000) 825-832.

[96] M. Łopaciński, J. Puszynski, and J. Lis, "Synthesis of Ternary Titanium Aluminum Carbides Using Self-Propagating High-Temperature Synthesis Technique". Journal of the American Ceramic Society 84 (2001) 3051-3053.

[97] Y. Zou, Z.M. Sun, S. Tada, and H. Hashimoto, "Synthesis reactions for $\mathrm{Ti}_{3} \mathrm{SiC}_{2}$ through pulse discharge sintering $\mathrm{TiH}_{2} / \mathrm{Si} / \mathrm{TiC}$ powder mixture". Materials Research Bulletin 43 (2008) 968-975.

[98] X. Wang, and Y. Zhou, "Solid-liquid reaction synthesis of layered machinable $\mathrm{Ti}_{3} \mathrm{AlC}_{2}$ ceramic". Journal of Materials Chemistry 12 (2002) 455-460.

[99] P. Sigmund, "Theory of Sputtering. I. Sputtering Yield of Amorphous and Polycrystalline Targets". Physical Review 184 (1969) 383-416.

[100] J.F. Ziegler, M.D. Ziegler, and J.P. Biersack, "SRIM - The stopping and range of ions in matter (2010)". Nuclear Instruments and Methods in Physics Research Section B: Beam Interactions with Materials and Atoms 268 (2010) 1818-1823.

[101] J.P. Baxter, G.A. Schick, J. Singh, P.H. Kobrin, and N. Winograd, "Angular distributions of sputtered particles". Journal of Vacuum Science \& Technology A: Vacuum, Surfaces, and Films 4 (1986) 1218-1221. 
[102] D.M. Mattox, Handbook of physical vapor deposition (PVD) processing : film formation, adhesion, surface preparation and contamination control. (Noyes Publications, Westwood, N.J., 1998).

[103] P.J. Kelly, and R.D. Arnell, "Magnetron sputtering: a review of recent developments and applications". Vacuum 56 (2000) 159-172.

[104] P.J. Kelly, J. O’Brien, and R.D. Arnell, "The production of porous and chemically reactive coatings by magnetron sputtering". Vacuum 74 (2004) 1-10.

[105] P. Eklund, M. Beckers, J. Frodelius, H. Högberg, and L. Hultman, "Magnetron sputtering of $\mathrm{Ti}_{3} \mathrm{SiC}_{2}$ thin films from a compound target". Journal of Vacuum Science \& Technology A 25 (2007) 1381-1388.

[106] J.E. Sundgren, B.O. Johansson, and S.E. Karlsson, "Mechanisms of reactive sputtering of titanium nitride and titanium carbide I: Influence of process parameters on film composition". Thin Solid Films 105 (1983) 353-366.

[107] A. Khatibi, J. Palisaitis, C. Höglund, A. Eriksson, P.O.Å. Persson, J. Jensen, J. Birch, P. Eklund, and L. Hultman, "Face-centered cubic $\left(\mathrm{Al}_{1-x} \mathrm{Cr}_{x}\right)_{2} \mathrm{O}_{3}$ ". Thin Solid Films 519 (2011) 2426-2429.

[108] G.B. Thompson, and D.D. Allred, "Reactive Gas Magnetron Sputtering of Lithium Hydride and Lithium Fluoride Thin Films". Journal of X-Ray Science and Technology 7 (1997) 159-170.

[109] R.J. McIntyre, "Reactive dc sputtering of cadmium sulphide films". Solar Energy Materials 7 (1982) 85-99.

[110] T. Larsson, H.O. Blom, S. Berg, and M. Östling, "Reactive sputtering of titanium boride". Thin Solid Films 172 (1989) 133-140.

[111] M. Beckers, N. Schell, R.M.S. Martins, A. Mücklich, W. Möller, and L. Hultman, "Nucleation and growth of $\mathrm{Ti}_{2} \mathrm{AlN}$ thin films deposited by reactive magnetron sputtering onto MgO(111)". Journal of Applied Physics 102 (2007) 074916.

[112] P. Eklund, M. Bugnet, V. Mauchamp, S. Dubois, C. Tromas, J. Jensen, L. Piraux, L. Gence, M. Jaouen, and T. Cabioc'h, "Epitaxial growth and electrical transport properties of $\mathrm{Cr}_{2} \mathrm{GeC}$ thin films". Physical Review B 84 (2011) 075424.

[113] J. Emmerlich, H. Högberg, S. Sasvári, P.O.Å. Persson, L. Hultman, J.-P. Palmquist, U. Jansson, J.M. Molina-Aldareguia, and Z. Czigány, "Growth of $\mathrm{Ti}_{3} \mathrm{SiC}_{2}$ thin films by elemental target magnetron sputtering". Journal of Applied Physics 96 (2004) 48174826. 
[114] H. Högberg, P. Eklund, J. Emmerlich, J. Birch, and L. Hultman, "Epitaxial Ti 2 GeC, $\mathrm{Ti}_{3} \mathrm{GeC}_{2}$, and $\mathrm{Ti}_{4} \mathrm{GeC}_{3}$ MAX-phase thin films grown by magnetron sputtering". Journal of Materials Research 20 (2005) 779-782.

[115] P.S. Darwin, Z. Jie, Z. Yanchun, M. Denis, and M.S. Jochen, "Synthesis and elastic properties of $\mathrm{V}_{2} \mathrm{AlC}$ thin films by magnetron sputtering from elemental targets". Journal of Physics D: Applied Physics 42 (2009) 185408.

[116] O.E. Dictionary, "sinter, v.". (Oxford University Press).

[117] R.M. German, P. Suri, and S.J. Park, "Review: liquid phase sintering". Journal of Materials Science 44 (2009) 1-39.

[118] Z.M. Sun, S. Gupta, H. Ye, and M.W. Barsoum, "Spontaneous growth of freestanding $\mathrm{Ga}$ nanoribbons from $\mathrm{Cr}_{2} \mathrm{GaC}$ surfaces". Journal of Materials Research 20 (2011) 2618-2621.

[119] S. Foner, "Versatile and Sensitive Vibrating - Sample Magnetometer". Review of Scientific Instruments 30 (1959) 548-557.

[120] R.C. Jaklevic, J. Lambe, A.H. Silver, and J.E. Mercereau, "Quantum Interference Effects in Josephson Tunneling". Physical Review Letters 12 (1964) 159-160.

[121] F. London, Superfluids. (Wiley, New York,, 1950).

[122] B.S. Deaver, and W.M. Fairbank, "Experimental Evidence for Quantized Flux in Superconducting Cylinders". Physical Review Letters 7 (1961) 43-46.

[123] R. Doll, and M. Näbauer, "Experimental Proof of Magnetic Flux Quantization in a Superconducting Ring". Physical Review Letters 7 (1961) 51-52.

[124] B.D. Josephson, "Possible new effects in superconductive tunnelling". Physics Letters 1 (1962) 251-253.

[125] P.W. Anderson, and J.M. Rowell, "Probable Observation of the Josephson Superconducting Tunneling Effect". Physical Review Letters 10 (1963) 230-232.

[126] A.H. Silver, and J.E. Zimmerman, "Quantum States and Transitions in Weakly Connected Superconducting Rings". Physical Review 157 (1967) 317-341.

[127] R. Hari, and R. Salmelin, "Magnetoencephalography: From SQUIDs to neuroscience: Neuroimage 20th Anniversary Special Edition". NeuroImage 61 (2012) 386-396.

[128] S. Karsten, and I.B. Alex, "Biomagnetism using SQUIDs: status and perspectives". Superconductor Science and Technology 19 (2006) S160.

[129] E. Keiji, T. Yuya, N. Kota, S. Teruyoshi, and Y. Takashi, "Biosensing utilizing magnetic markers and superconducting quantum interference devices". Superconductor Science and Technology 30 (2017) 053002. 
[130] H. Kuma, H. Oyamada, A. Tsukamoto, T. Mizoguchi, A. Kandori, Y. Sugiura, K. Yoshinaga, K. Enpuku, and N. Hamasaki, "Liquid phase immunoassays utilizing magnetic markers and SQUID magnetometer". Clinical Chemistry and Laboratory Medicine 48 (2010) 1263-1269.

[131] S.V. Vonsovski1, Ferromagnetic resonance; the phenomenon of resonant absorption of a high-frequency magnetic field in ferromagnetic substances, 1st English ed. (Pergamon Press, Oxford, New York,, 1966).

[132] L.D. Landau, and E. Lifshitz, "On the theory of the dispersion of magnetic permeability in ferromagnetic bodies". Physikalische Zeitschrift der Sowjetunion 8 (1935) 153.

[133] J. Griffiths, "Anomalous high-frequency resistance of ferromagnetic metals". Nature 158 (1946) 670.

[134] E. Zavoisky, "Spin magnetic resonance in the decimeter-wave region". Journal of Physics USSR 10 (1946) 197-198.

[135] V. Arkad'ev, "The Reflection of Electric Waves from a Wire". Soviet Physics Journal of Theoretical and Experimental Physics 45 (1913) 312.

[136] T.L. Gilbert, "A phenomenological theory of damping in ferromagnetic materials". Ieee Transactions on Magnetics 40 (2004) 3443-3449. 


\section{Papers}

The papers associated with this thesis have been removed for copyright reasons. For more details about these see:

http://urn.kb.se/resolve?urn=urn:nbn:se:liu:diva-145679 